\title{
A Review and Insights for Eleven Years of Urban Microclimate Research Towards a New Egyptian ERA of Low Carbon, Comfortable and Energy-Efficient Housing Typologies
}

\author{
Mohammad Fahmy 1,*(D), Sherif Mahmoud ${ }^{1}$, Ibrahim Elwy ${ }^{1}$ and Hatem Mahmoud 2,3(D) \\ 1 Department of Architecture Engineering, Military Technical College, Kobry El-Kobba, Cairo 11662, Egypt; \\ sherif_ahmed@mtc.edu.eg (S.M.); ibrahim.elwy@mtc.edu.eg (I.E.) \\ 2 Department of Architecture Engineering, Engineering Faculty, Aswan University, Aswan 81542, Egypt; \\ hatem.mahmoud@aswu.edu.eg \\ 3 Environmental Engineering Department, Egypt-Japan University of Science and Technology E-JUST, \\ New Borg El-Arab City, Alexandria 21934, Egypt \\ * Correspondence: md.fahmy@mtc.edu.eg
}

Received: 6 January 2020; Accepted: 24 February 2020; Published: 28 February 2020

\begin{abstract}
Since the mid-1970s, urban development in Egypt has sprawled far from the distinguished compact arid built environment, as the court-yarded housing typologies that completed the vernacular picture of desert architecture have been discarded in the early 20th century. This has motivated urban microclimate research in Egypt. The main objective was initially to improve outdoor thermal comfort. Therefore, Egyptian research started with assessing different existing patterns for the sake of climate responsive and sustainable urban design practice characterized with low carbon, thermal comfort and energy efficiency in such a hot arid conditions. That is why the review workflow of this article has followed a design progress workflow that led to solving design complexities with regard to generating housing urban forms on a microclimate basis rather than an article regular review workflow in order to extract the research gaps and conclude insights. After discussing a general framework for generating housing sustainable design identified from the concluded gaps, the main conclusion is a vision and a call to integrate the Urban microclimate-Building passiveness-Renewables design dimensions, UBR, towards the evolution of a new era of energy efficient housing typologies and a 5th generation of Egyptian sustainable cities where the $1^{\text {st }}$ generation of new Egyptian cities started 1970s.
\end{abstract}

Keywords: urban microclimate; clustered urban form; GreenSect; housing typologies; Egyptian cities

\section{Introduction}

Like most developing countries, Egypt witness a rapidly increasing urbanization. The population growth and urban development have caused city-induced climate changes [1]. While Egypt has a minor impact on the global greenhouse gas (GHG) emissions ( $0.6 \%$ of global emissions), GHG is one of the main parameters affecting climate change in Egypt [2-4]. Egypt is considered as one of the countries highly vulnerable to climate change [5]. By 2060, as a result of global warming, the average temperature in Cairo, capital of Egypt, is expected to increase by $4{ }^{\circ} \mathrm{C}$, and for the rest of Egypt, by 3.1 to $4.7^{\circ} \mathrm{C}$ [6]. Under an extreme emissions scenario, the increase in temperature is expected to be $5.6^{\circ} \mathrm{C}$ during the period 1990 to 2100 . If emissions decreased dramatically, the increase in temperature would be under $1.6^{\circ} \mathrm{C}$ [5]. The increasing global research attention to the thermal conditions of the built environment is due to the high level of health-related risks due to the climate change. For instance, 
the European heat waves in 2003 resulted in between 25,000 to 70,000 deaths throughout Europe [1]. This problem has stimulated Egyptian researchers to investigate the adverse effects of urbanization on outdoor thermal conditions of existing cities and new cities which are mostly located in desert regions.

The American society of Heating, Refrigerating and Air-Conditioning Engineers (ASHRAE) has defined the thermal comfort as the state of mind which expresses satisfaction with the thermal environment [7]. The outdoor thermal performance is influenced by various parameters, such as the arrangements of buildings, shaded areas, materials albedo, water bodies, orientation and space aspect ratio. It is important to investigate the impact of manipulating those variables in the early stages of urban and architecture design process. In this regard, this review article started to collect, and analyze the studies published in the Egyptian urban microclimate research field since 2008 when the first study on Egyptian urban forms was published to numerically investigate the mutual effects between different existing patterns (dot-clustered-compact) and the microclimatic conditions. The lack in the urban microclimate studies in the Egyptian context dedicated to physically designing urban forms especially concerning half of the land use budget, residential buildings, directed the authors of the aforementioned reference towards defining the corresponding thermal performance and in turn estimating the pedestrian thermal comfort, energy efficiency and the negative effects of those different patterns in later studies [8]. Since then, many other investigations have been dedicated to design residential neighborhoods on a climate responsive basis [9]. In this concern, achieving thermal comfort as a cumulative parameter that represent a good design of urban form, is very difficult to be conducted passively, especially during summer when it is very warm [10] despite that, an enhancement in thermal comfort is possible through interventions in the design of urban buildings. Moreover, the outdoor thermal performance in shape of air temperature and solar radiation significantly influence the indoor thermal performance through windows and building envelop, thus improving the outdoor will improve the indoor climate and reduce the cooling and heating loads.

From this stance, this study aims to present a review of studies published over the last eleven years on the behavioral and energy efficiency aspects of the outdoor environment in Egypt. It seeks to contribute towards a more in-depth understanding and assessing the present situation of the related researches in Egypt to identify the knowledge and applied practice gaps and steps towards a new Egyptian era of housing environment. In Egypt, buildings contribute to $67 \%$ of electricity consumption [11], and $42 \%$ of energy consumption [12], whereas housing that represents about $50 \%$ of the Egyptian built environment, contributed to $51.3 \%$ of electricity production [11], $19 \%$ of energy consumption and $9.7 \%$ of carbon emissions, [2,13]. That is why much of the Egyptian microclimate research described in this review focused on the urban form design of housing built environment. Further, that is why the review workflow of this article has followed a design progress workflow which concluded a research line that pulled many researchers in Egypt (Figure 1). In this review article, the survey of this research line was designed to filling the knowledge gaps and solving the complexities with regard to the connection between microclimate and the housing urban forms rather than an article regular review workflow.

\section{Methodology}

The workflow of this review article is not a regular classification, but rather it is built along research line that followed the idea of how to design, select, model, simulate and/or assess the effect of different alternatives of each element of the residential built environment, fabric-network-vegetation, on the most common sustainability measures; comfort, energy and carbon emissions in such a hot arid country like Egypt. This study did the review not in the regular traditional way of a review article; it focuses on the last eleven years of Egyptian studies that have addressed the impacts of urban form (fabric and network), mitigation, and adaptation strategies on the outdoor thermal performance which had implications on the evolution and design of residential buildings and their carbon emissions, thermal comfort and energy efficiency. 
The study is divided into four main parts. The first (Section 3) reports the studies on the impact of urban patterns (geometry) on outdoor thermal conditions (fabric effects) through the publications that involved Egyptian case studies. Urban geometry aspects were categorized into aspect ratio $\mathrm{H} / \mathrm{W}$, sky view factor (SVF), street orientation, and neighborhood configuration. Moreover, this part will address the studies that incorporated energy aspects. The second (Section 4) presents the research on the adaptation and mitigation strategies through the publications that had also Egyptian case studies. The surface material albedo and vegetation species are examples worth mention among the mitigation and adaptation strategies. The third part (Section 5) presents the methods that have been applied to investigate urban microclimate research case studies in Egypt. Finally, the fourth part (Section 6) will present the urban microclimate research gaps and what can be proposed in Egypt for the sake of developing a new ERA of housing typologies on a climate responsive basis.

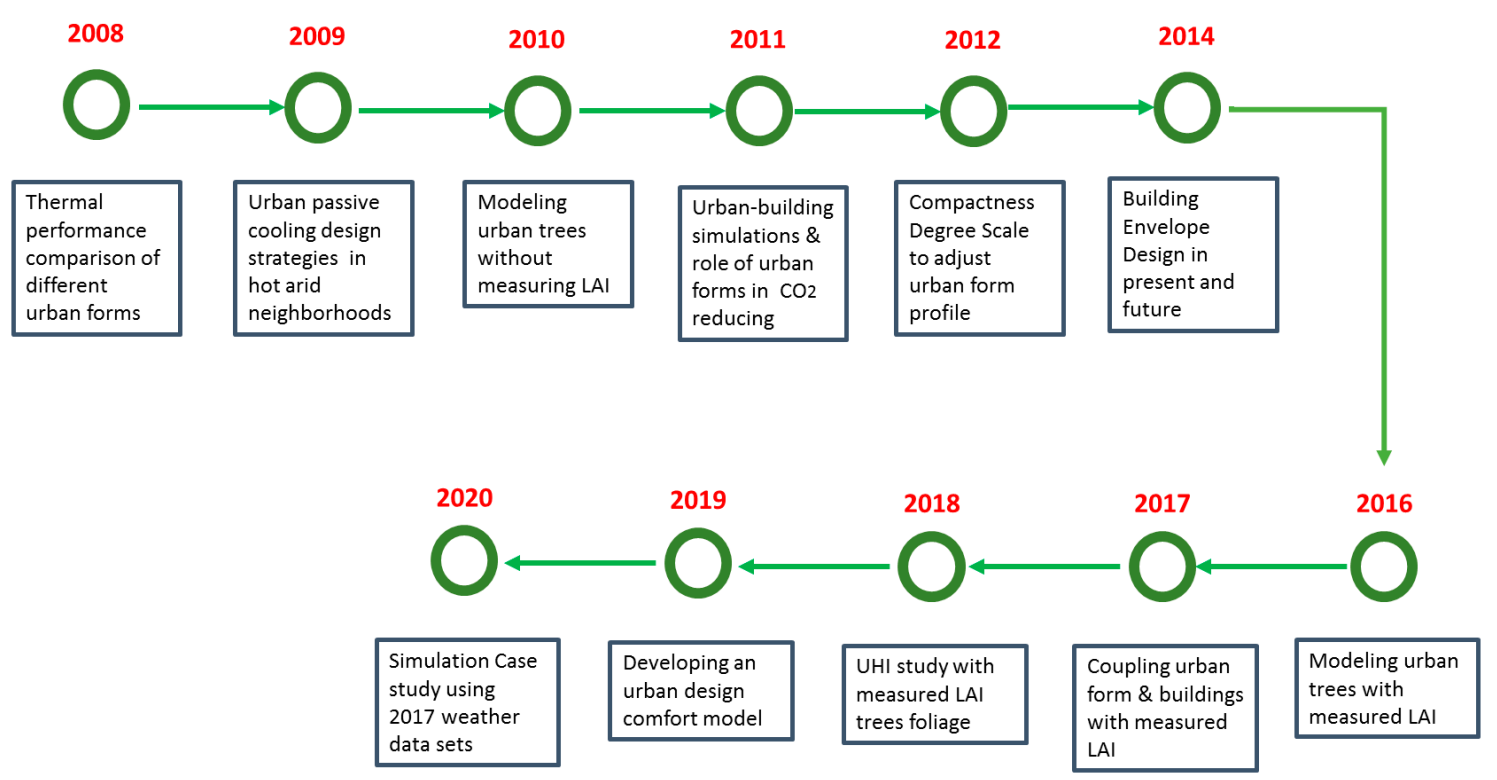

Figure 1. A brief for the design complexities and milestones that have been solved by the research line reviewed in this article, (2008-2020).

\section{Research for urban fabric geometrical adjustments}

\subsection{Urban Patterns Thermal Comfort Assessment}

Built environment elements-fabric, network and vegetation-have a swinging and mutual effect with the micro and local climate scales that reveal different sites' conditions. The effect appears in the main sustainability measures, either inside or outside the building such as thermal comfort, energy consumption and carbon emissions, as well as urban heat island (UHI) generation which in turn affect the energy consumption and carbon emission cycle again [14-18]. Specifically, in hot arid regions where both fabric and network receive a huge amount of solar radiation, there is still a lack in the application of climate knowledge to the urban development projects [19-21]. This is due to the increased population that needs vast actions to be accommodated. In a country like Egypt, the housing policies depend on the multifamily multistory dot pattern developments. However, such an overwhelming point cannot justify the lack of urban fabric geometry adjustments to alleviate arid conditions. As housing land use budget reaches $50 \%$ of neighborhoods, urban fabric geometry controls the solar radiation coming to surfaces through aspect ratio, sky view factor, orientation and compactness as urban passive cooling applications for the shading and ventilation strategies [22-25]. Urban canyons' microclimates and related thermal comfort studies are defined in literature by their aspect ratio $\mathrm{H} / \mathrm{W}$, and by their SVF [19,26-28]. For a whole pattern, a study in Cairo mentioned that urban geometry can be adjusted through defining the built-up volume of a neighborhood-the compactness degree. This is because 
there is no sole solution for excessive heat stresses $[29,30]$ in hot dry climates, to the extent that using some sensitive, intelligent and responsive design elements such as the traditional courtyard [31-33] is not sufficient [34], and the solution has to be comprehensive.

Nevertheless, it is essential to understand the interaction between the prevailing climate and the urban form prior to assessing the outdoor thermal comfort achieved by the diverse of urban forms $[35,36]$. Fahmy and Sharples assessed and analyzed three cases of urban designs using ENVI-met CFD numerical simulations [8]. The first form is compact and possesses high thermal performance during the daytime only, yet it hasn't enough wind access besides its high population density that affects the inhabitants' health. The second form is a medium density fabric that allows both enough wind speed and solar access for passive cooling- and health-related aspects. Nevertheless, its canyon aspect ratio does not provide enough shelter at higher solar altitudes, which can be enhanced by applying vegetation and urban trees. The third urban form is the dot single and multi-family urban form that provides enough wind flow, but more surfaces are subjected to direct radiation, but it involves more land consumption and urban sprawl that need more vegetation and green coverage when compared with the previous cases. Furthermore, Mahmoud [35] concluded that the appropriate urban form with its SVF and the intensity of direct vertical solar radiation are of a drastic influence on the thermal comfort of the outdoor spaces. Fahmy and Sharples, [8] concluded that the thermal comfort can be achieved by using spatial networks with precise orientation selection and by using fabric unit with urban spaces to provide an adequate compactness degree for specific housing and population while allowing wind flow through the urban spaces for passive cooling. From these viewpoints many other researchers have contributed to the analysis of urban patterns in order to suggest design instructions based on the mutual effects of built environment on microclimate and vice versa. Fahmy [37] reviewed the patterns of urban formation applied to Greater Cairo based on the vehicular network and the shape of the fabric. Vehicular network is divided into; (a) Grid type includes (normal grid and the branched grid), (b) hierarchical type (radial and longitudinal routes with long routes), (c) organic type, (d) mixed type. Same author referred to the shape of the fabric as a method of classification: it refers to the buildings, which is divided into: (a) point or dot shape patterns, (b) linear shape patterns, (c) compact shape patterns. It has been realized that different urban forms act thermally in different ways. Therefore, Shalaby and Shafey [38] optimized street canyon orientations with the aspect ratio in a hot eastern site in Egypt to increase daytime thermal comfort levels while mitigating nocturnal UHI. They found that north-south oriented streets are better in daytime provided that aspect ratio proportion is 1:3, which in addition permit an acceptable amount of heat release starting from evening. In the east-west oriented streets, a limited impact of increasing aspect ratio daytime is noticed and therefore a 1:1 proportion is recommended. The paper also finds that the diagonal urban form with 1:2 and 1:3 aspect ratios given to its NE and NW streets, respectively, is thermally the best along the day on average.

\subsection{The Compactness Degree Scale}

As the aspect ratio of an urban form, canopy asymmetries, vertical properties, shading effects and irradiated surfaces control urban canyon thermal behavior which means a specific degree of compactness of in a certain city zone can control the total heat exchange process [26]. Fahmy and Sharples [34] introduced the compactness degree terminology to define the overall degree of compactness of urban site as the aspect ratio represents only a single canyon in the site. The Compactness Degree Scale (CDS), defines the built-up volume from 0.1 to 10 calculated by multiplying the general floor area ratio of an urban site by the average floor number in this site. The 0.1 unit less value represents a site with only $10 \%$ of general floor area ratio multiplied by only one single floor whereas the 10 value is approximated after a site with 12 floors having $80 \%$ of general floor area ratio.

It is the product of the total local urban construction percentage times the average number of floors of the local canopy layer. Moreover, Fahmy [39] calculated empirically the compactness degree scale (Dc) to adapt forms to its corresponding climate change scenario. This scale is classified into five 
categories on the transect of a city (Table 1), to help comparing the overall thermal performance of a neighborhood to another on a built-up volume basis not on a single street canyon geometry basis.

Table 1. Categories and ranges of the compactness degree scale [34,39-41].

\begin{tabular}{cccc}
\hline No. & City Sector & Corresponding Compactness Category & Compactness Degree \\
\hline 1 & City center & Very compact & $5-8$ \\
2 & Central urban & Compact & $2.8-5$ \\
3 & General urban & Medium & $1.6-3$ \\
4 & Suburban & Open & $0.4-1.8$ \\
5 & Rural urban & Very open & $0.3-0.5$ \\
\hline
\end{tabular}

\subsection{Development of an Urban Passive Thermal Comfort System}

Thermal comfort depends on the radiant exchanges represented by the mean radiant temperature which is affected by the fabric compactness. The thermal comfort assessment and measurement cannot be dependent on the theoretical heat balance when studying the inhabitants' thermal behavior in reality. Fahmy and Sharples [34] introduced an urban passive thermal comfort system, to utilize two elements: (1) the urban fabric form with its green structure; and (2) thermal comfort adaptation by introducing urban green scene stimulation. Moreover, the study proofs that the parallel avenues clustered form act climatically well, if the Dc is to be studied considering the local land use and housing that needs design, taking into consideration the thresholds of population. Also, the study demonstrates an approach towards green structuring and urban patterns geometrical adjustments on a climate basis, as well as, it illustrates that the outdoor thermal comfort levels are dependent on: (1) the form design details; (2) its vegetation; (3) orientation of both the canyon axes; and (4) linear trees arrangement. Furthermore, Hassan and Mahmoud [42] studied the urban surface structure in an urban park, in which these variations in the urban surfaces affect surrounding microclimate and in turn affect the human's thermal comfort through measuring of the PET. Also, these differences in microclimates owing to different solar radiation and wind speed, in which these two factors resulted in variation in the mean radiant temperature and PET that impacts human's thermal perception. Moreover, Limona et al. [43] had examined three layouts in the coast of Baltim in Egypt to stand for the best urban form that enhance the outdoor microclimate and improve human thermal comfort. The results had proved that the outdoor comfort in the three different urban layouts differ depending on the air temperature, wind speed, relative humidity, and the predicted mean vote (PMV), emphasizing that urban geometry parameters have impacted the human thermal comfort based on the orientations, volume of buildings, width of the streets.

\subsection{Development of an Urban Thermal Comfort Design Model}

There are two main aspects that play a crucial role in modifying arid microclimates in city planning, which are the neighborhood fabric and vegetation. Yet, Fahmy et al. [44] discussed other parameters affecting the arid microclimates, which are compactness degree, grass coverage, leaf area density, trees ground coverage, and asphalt and building areas. There are numerous mutual effects between built environment elements, fabric, network and vegetation that affect the microclimate change, in which these parameters should be taken into consideration when developing the urban design comfort model (UDCM) (Figure 2). 


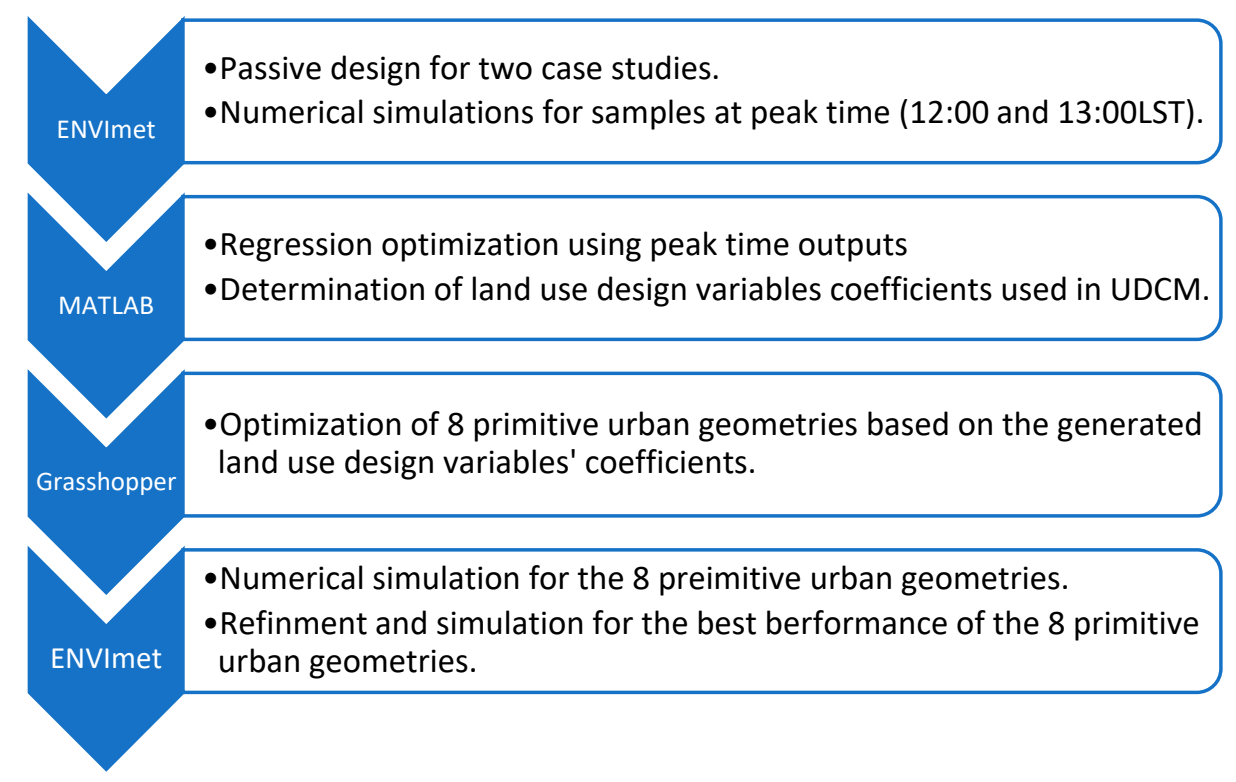

Figure 2. UDCM research methodology workflow.

\subsection{The Clustered Urban Form: from Cairo to Aswan}

This section will discuss the different urban cluster forms and how they affect the mean comfort level. Fahmy and Sharples [45] suggested three urban forms for a case study of a dot pattern of a single family villas, in New Cairo settlement (Egypt), which are: (1) clustered urban form planned over the base case zoning to examine the effects of clusters regardless the orientation; (2) using the same land uses percentage but allocated in different zones; (3) using the same master plan of the previous case but applying different albedo for walls and roofs. The study used PMV as a scale for pedestrian thermal comfort. It has been developed originally for the assessment indoor conditions and doesn't represent adaptation effects; however, PMV scale in ENVI-met calculations is not the regular PMV scale of Fanger. PMV was used when ENVI-met as an assessment tool that models all outdoor environment element, didn't have the PET yet. In the previous versions of ENVI-met it used an improved PMV for outdoor conditions after the work of Jendritzky and Nübler to account for the outdoor wind speed and all net wave radiation [46], however, much discussion can be found in the work of d'Ambrosio et al., for the calculation issues of the original Fanger PMV [47]. Considering that the three design suggestions have $8 \mathrm{~cm}$ grass and $15 \mathrm{~m}$ height Ficus elastica trees, the results of this study showed that the first design suggestion reduced the external thermal comfort with range $0.1-0.7$ than the base case. The other two design suggestions have the same thermal behaviors due to the similarities in the zoning, however they are different from the base case and the design suggestion as the former's comfort peak is displaced forward due to the increased compactness degree that provides more direct shelter. Contrarily, in the evening the behavior of the second and third suggestions differs also from the base case and the first design suggestion in which the PMV $=0$ increased by 0.6-1.4 from early evening until sunset. This may be attributed to the increased number of dense trees which increase the amount of long-wave radiation from the ground near the walls that is trapped by the tree's canopies. Therefore, the local scale clustered form with dense tree arrangement delayed heat gain during the day and reduced cooling overnight. Hence, the usage of high albedo roof in the third design suggestion prevent majority of short-wave radiations to be absorbed by the building fabric resulted in lower level of PMV0 when compared with the second case. Further, Mahmoud [35] investigated the effect of the urban form on the outdoor thermal comfort in New Aswan (Egypt) that aimed to identify the suitable model for the urban geometry concerning the environmental point of view. The study found that there was a wide range of Physiological Equivalent Temperature (PET) values between the 
examined cases due to the shape of the SVF and orientation in which these variations led to relatively comfort spaces and discomfort spaces with extreme heat stress.

\subsection{Connecting Outdoor-Indoor Environments}

There is a strong relation between the outdoor urban thermal performance and the indoor environmental quality (IEQ), such that IEQ is the result of indoor thermal comfort, indoor air quality (IAQ) acoustic and visual comfort, [48,49]. In a study that took place in the Egyptian environment, urban trees' effects on the occupant thermal comfort has been studied in a residential building [50]. Another study investigated the effect of baseline and two urban cluster form alternatives on the outdoor predicted mean vote (PMV) that was used to quantify thermal comfort, as well as, their effect on a building occupant thermal comfort and its $\mathrm{CO}_{2}$ emissions [45]. The study found that urban passive deigns strategies and their applications in terms of orientation towards prevailing wind and clustering the housing are much efficient and shifts the PMV peak output two hours later from the noon time and improves buildings IEQ in comparison to the baseline and reduced the annual carbon emissions. Such shift is owed to the clustered urban form which has been called hybrid urban form when associated with a green infrastructure and revealed an urban thermal mass and urban time lag, (Figure 3).

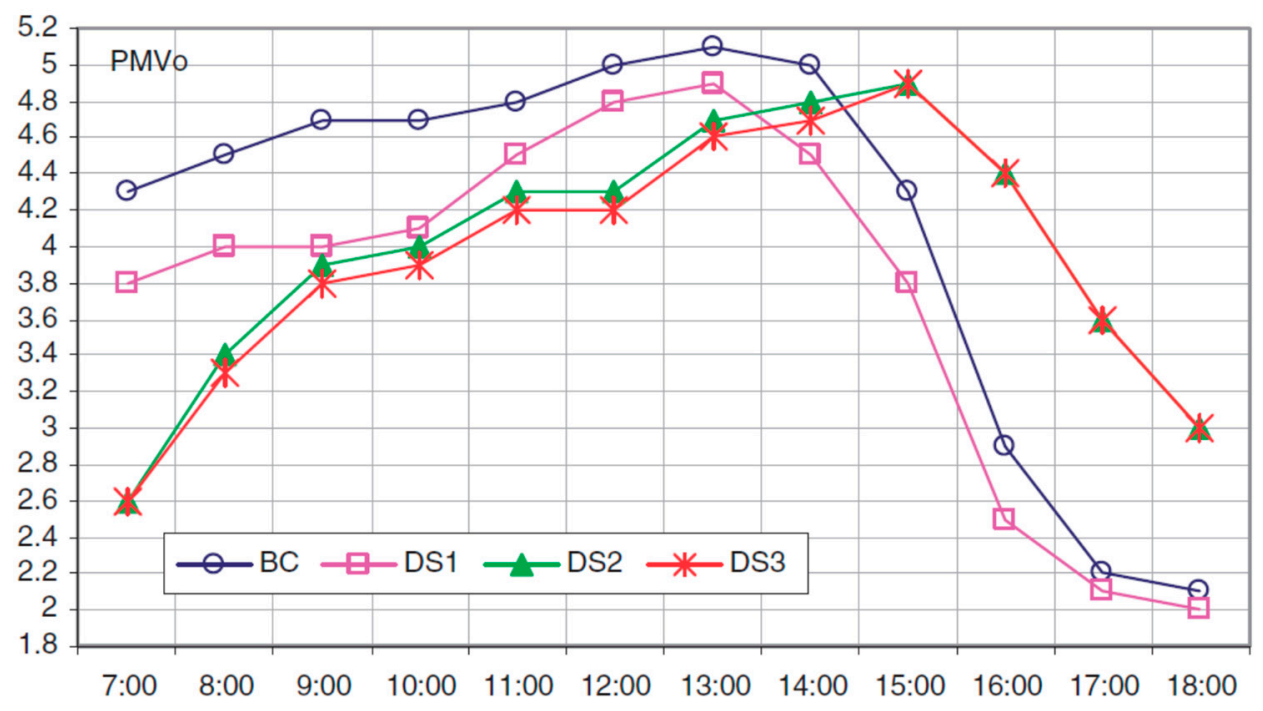

Figure 3. The figure illustrates that an urban form with comprehensive passive design applications concluded a shift in heat gain, loss and an urban time lag of about $2 \mathrm{~h}$; Bas case (BC), design suggestion no.1 (DS1) is a clustered housing over the same vehicular network, design suggestion no. 2 (DS2) is a newly designed clustered housing with adjusted aspect ratios and green infra over a new vehicular network, whereas DS3 is the same as DS2 but with higher albedo for building surfaces and asphalt roads. It has to be noted that curves in Figure 2 report modified PMV values according to Jendritzki and Nubler [46].

Moreover, Abdallah [51] investigated the influence of outer courtyards between buildings using two types of courtyards: (1) shallow canyons with $\mathrm{H} / \mathrm{W}$ ratio $0.24-0.6$ that is located in the urban pattern of youth housing sector in New Assuit city; and (2) deep canyons with H/W ratio of 4 in one of the new residential houses in El-Abrahimia and El-Moalemeen complexes in the center of Assuit city. According to a comparison that was conducted between the two cases based on; the indoor thermal comfort, energy consumption, and IEQ, the study revealed that there was a reduction of the indoor temperature of the spaces that overlooked the deep canyons with a difference of $11^{\circ} \mathrm{C}$ from the outdoor temperature, and the indoor temperature reaches the upper limit of $90 \%$ acceptable range of ASHRAE. 


\section{Urban Adaptation and Mitigation Strategies Research}

Vegetation is widely recognized as a major player in enhancing microclimatic conditions for the many benefits it supports: sound comfort, pollution reduction, aesthetic values, social habitat in addition to the energy savings in buildings owing to the lesser cooling or heating loads [52]. Urban vegetation acts through three main characteristics, which to a large extent, affect the climate; basically shading, evapotranspiration and wind blockage [53,54]. In this concern, within urban street canyon, the influence of vegetation is found to be dependent on the green-to-built-up area ratio, i.e.,; size, density, shape, age, species, site case of the plant [55] along with grouping and orientation as well [56-58].

Urban trees represent an important element of site vegetation, which it can improve the microclimatic performance of built environment, adapt patterns to climate change and reduce energy consumption [59,60]. Tree microclimate arises based on radiation intercepted and evapotranspiration. The canopy parameters Leaf Area Index (LAI), and Leaf Area Density (LAD), contribute to canopy shading and to the circulation of water through tree roots-trunk-foliage system [54,61-63] which leads to lowering air temperatures [64] and bettering comfort levels in and out buildings if accompanied with urban fabric geometrical adjustments $[26,65,66]$. Radiation interception occurs due to canopy blocking of short and long-wave radiation from the upper hemisphere, whereas evapotranspiration occurs relying on the water content carrying capacity of the soil-tree-air. Evaporation happens from the surface of leaves to air, and transpiration happens from soil to stem and leaves according to the photosynthesis process. These processes resulted in increasing is latent heat and decreasing of sensible heat within the tree leading to lower air temperature, less heat gain for surrounding air, and in turn achieve better outdoor and indoor thermal comfort. Based on the previous discussion, selection of urban trees can be based on thermal performance that depends on: (1) foliage characteristics; (2) total height and canopy geometry; (3) botanical aspects such as (type of soil, tree deciduousness, depth and radius of roots, and capability of bearing the hazards and harsh conditions. Studying urban trees should thus be based on two environmental canopy modeling parameters, which are LAI and LAD, as will be illustrated in the following subsections.

\subsection{Assessing Urban Trees Numerical Parameters Without Measurements}

LAI and LAD are the main foliage parameters needed to model radiation through a tree a canopy and between a tree and its environment. It can be estimated utilizing field measurement or using instruments and empirical models. There is lack of research concerning LAI and trees modeling in hot regions, as well as, the urban trees modeling to access their thermal effect in contact with buildings in hot arid regions. Hence, there is an urge need to model trees even without LAI or LAD sources for specific species, and it is essential to know the preferred LAI of tree to produce maximum shadow at peak hour of a mid-latitude site. following Lalic et al. [67], Fahmy et al. [59] developed an empirical method to model LAD values of a mid-latitude urban tree and its effects at peak time without the need to measure LAI which is an essential parameter to introduce trees LAD foliage values to the vegetation database of ENVI-met microclimate CFD model [68].

LAI definition of flat leaves reveals its calculation. It is equal to the upper leaves area divided by the tree ground planting area, at peak time if the shadow is solid, and then the ground planting area is equal to the projected ground shadow of the tree. Moreover, the maximum projected ground shadow of the tree is at the maximum solar altitude; therefore, the least value of LAI to produce a solid ground shadow at peak time is when the leaves area equal to projected shadow area and the LAI value is equal to 1 . Hence, $\mathrm{LAI}=1$ can be used as a reference value for urban trees of semi-arid Mid Latitude region in which Egypt lies (Figure 4). Using this empirical methodology, Fahmy, et al. [50] had investigated the influence of using two types of trees ( $15 \mathrm{~m}$ high Ficus elastica, and $20 \mathrm{~m}$ Yellow poinciana) on the indoor thermal comfort represented in PMV. The study concluded that $15 \mathrm{~m}$ high Ficus elastica achieved better thermal comfort, which came to conclusion that urban developments in Cairo, Egypt should consider not only trees planting, but also the type of trees during the planting stage. Continuing the research 
streamline, the coupled outdoor-indoor (urban-building) simulations, Fahmy, et al. [60] discussed the benefits of applying urban green cover and its effect on domestic energy efficiency in present and future. Two different urban cases were examined using green cover and the results showed the effect of the different urban microclimates on the energy consumptions and energy savings even the same domestic residential buildings were used in the two cases. Figure 4 indicates the empirical idea of solving the modeling calculations to add Egyptian environment trees to ENVI-met database.

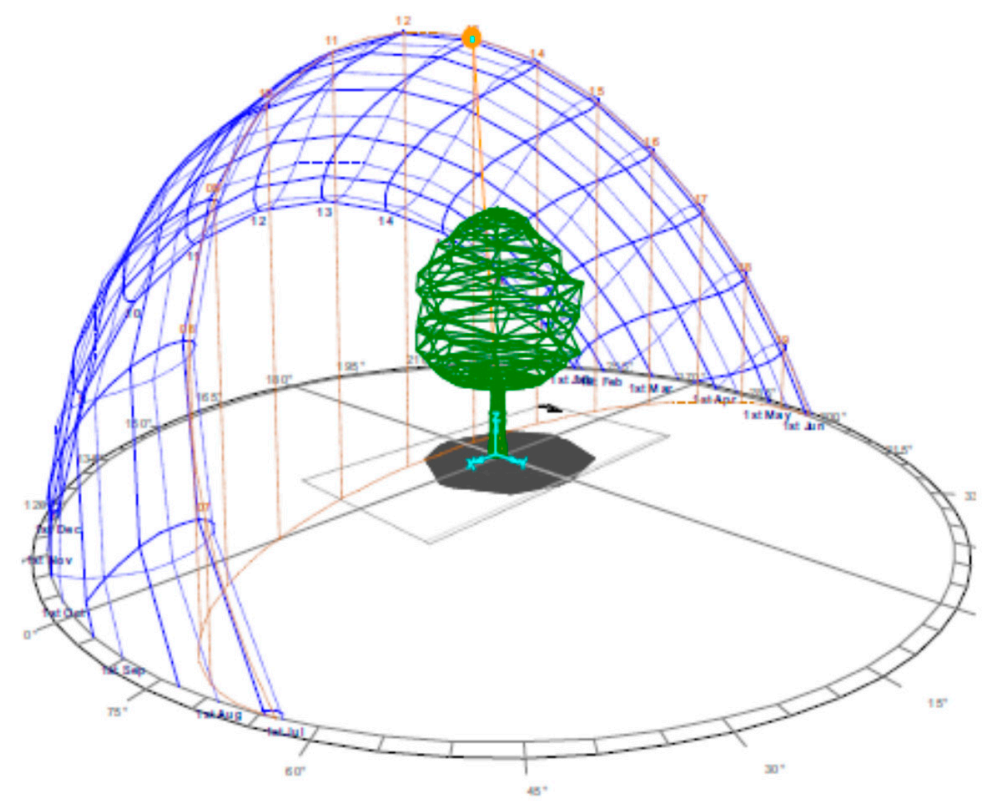

Figure 4. A 3D modeling for the solar path diagram of Cairo at 13:00LST (Local Solar Time) indicates an altitude angle of $82^{\circ} 40^{\prime}$ which is empirically generated an LAI of at least 1 to conclude a ground solid shade of flat leafs urban trees.

\subsection{Assessing Urban Trees with Measured LAI and Albedo}

In order to assess the complete built environment elements, urban trees real foliage has to be modeled on real LAI basis rather than an empirical one to assess trees role in modifying their urban environments' thermal performance [69]. Therefore, a four stages methodology has been applied in case study in Borg El-Arab (Alexandria, Egypt) to compare the thermal performance of urban spaces that applied urban trees, once modeled empirically and another modeled on a measured LAI and Albedo basis [69]. The measurement experiment applied a LAI2200c plant canopy analyzer [70] and the use of two back to back CMP21 second class high temperature pyranometers as albedometers, [71]. Those four steps can be summarized as following; (1) field measurements of albedo and LAI and observations of the trees geometry; (2) digitizing and recomputing the tree initial measurements; (3) modeling the selected local trees numerically to be added to the simulation tool; and (4) and finally modeling and simulation of the urban site selected to assess trees within its built environment. It is found that the modeled trees on a measurement basis for LAI and Albedo are thermally performing better than those empirically modeled and that a database for urban trees on LAI measurement basis is needed (Figure 5). 


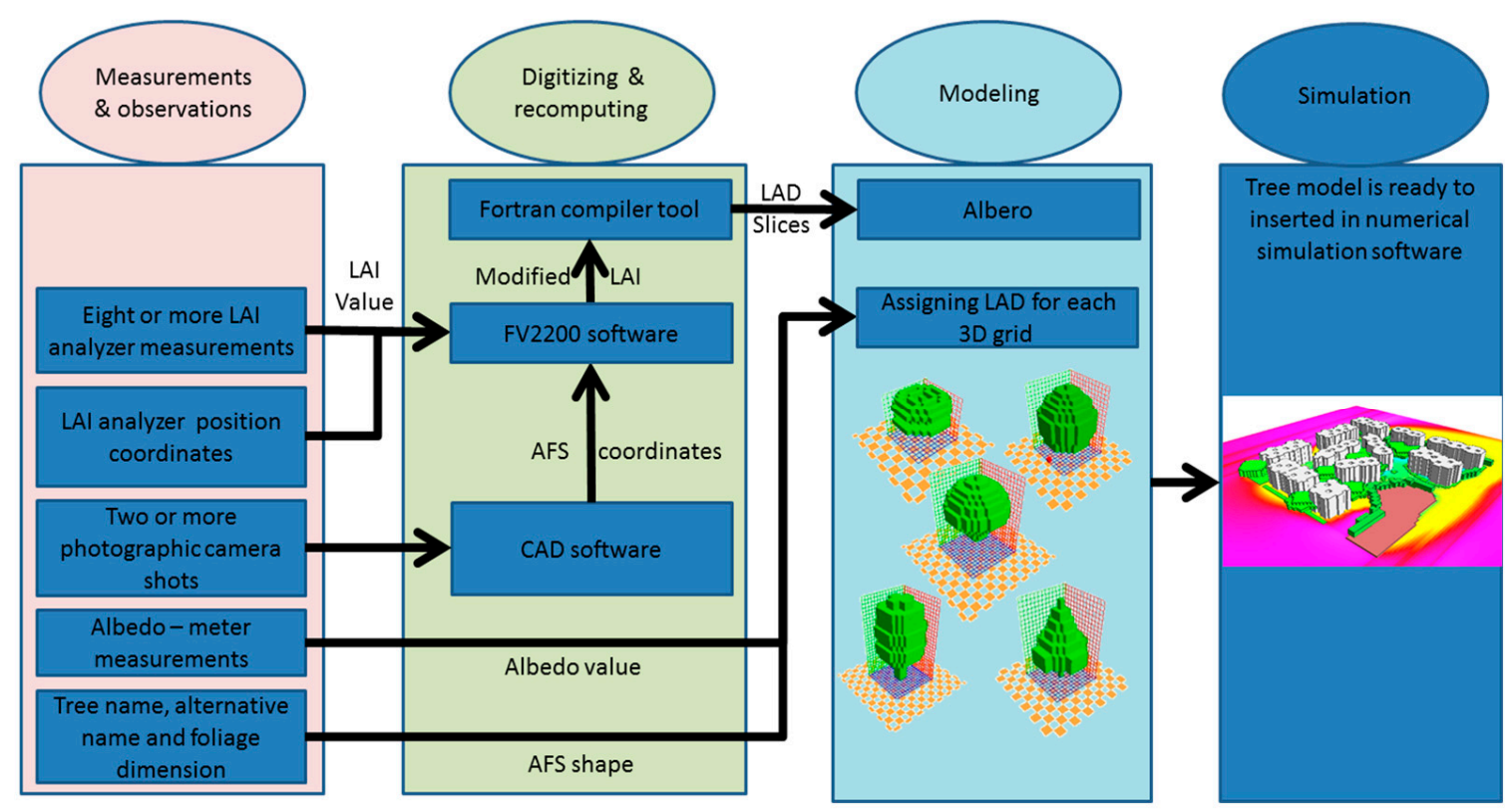

(a)

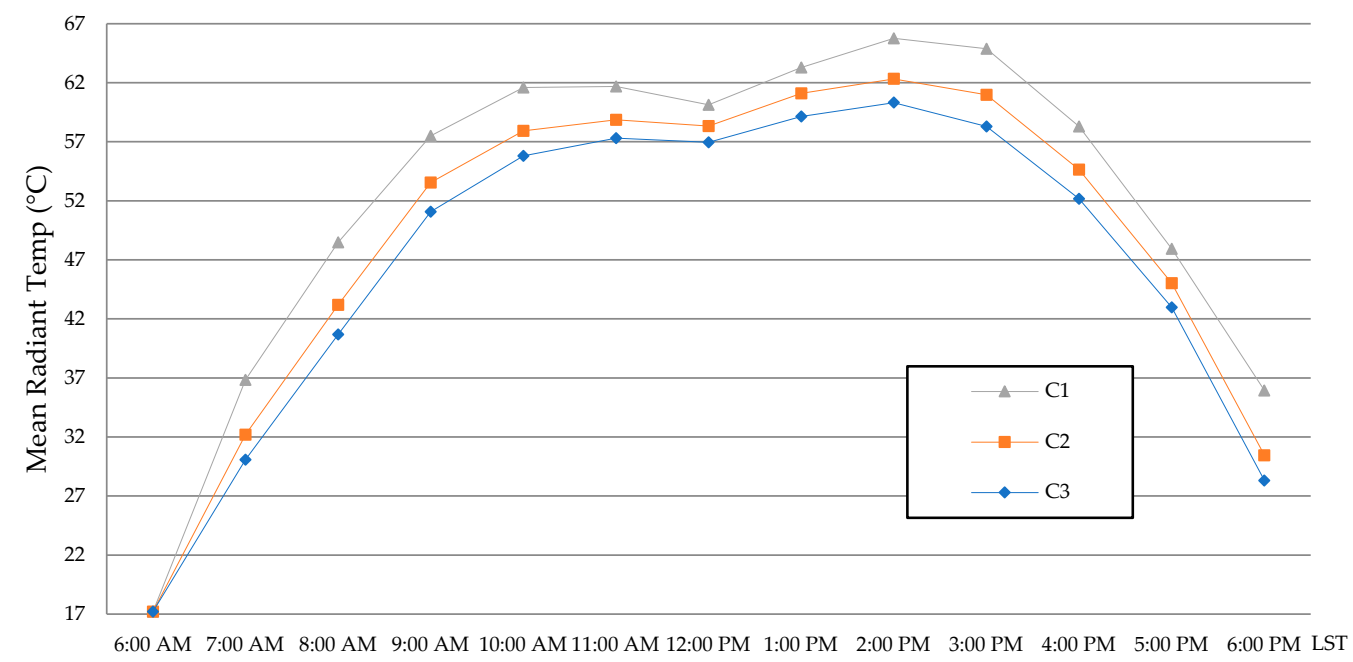

(b)

Figure 5. (a) Methodology of generating LAD values to simulate a single (isolated) tree in meteorology numerical simulation software, [60,69]. (b) $T_{\text {mrt }}$ comparisons between different cases of a site in Alexandria, Egypt; $\mathrm{C} 1$ is without trees, $\mathrm{C} 2$ is with trees of $\mathrm{LAI}=1$, and C3 is the site with measured LAI.

\subsection{UHI Mitigation}

Urban heat islands have been investigated in Cairo from a thermal effect point of view in the work of Hamid et al. [72] and it was found that Land Surface Temperature (LST) which is the Surface Urban Heat Island (SUHI) in new towns is $2 \mathrm{~K}$ warmer than in Cairo due to the non-uniform distribution of urbanization. Moreover, the study indicates that the selection of suitable rural references in SUHI 
studies is an important in a desert city with significant landscape and surface difference with their most surrounding areas such as Cairo. However, as intelligent, innovative, and aesthetic urban environment element, trees patterns and lines mitigate urban heat island.

In the study of Fahmy et al. [73], the mitigation of UHI took place in Cairo in present and future by the application of tree lines, green roofs, high albedo pavements and shading structures mentioned in the green rating system LEED-ND, and the microclimatic numerical model ENVI-met was the assessment method. The study proved the efficiency of using selected Egyptian trees lines in UHI mitigation in present and under climate change scenarios until the end of century (2020, 2050 and 2080) in terms of air and radiant temperature reductions.

In the research of Yasser [74], tree ground coverage percentages improved pedestrian thermal comfort by maximum of $6{ }^{\circ} \mathrm{C}$ on the PET scale, and with a minimum of $2{ }^{\circ} \mathrm{C}$ but with a wind speed reduction ranging from $0.2-1.0 \mathrm{~m} / \mathrm{s}$ in two street canyons; one of them is NE-SW axe and the other is NW-SE axe. The trees coverage percentages were best for the NE-SW axe canyon with $50 \%$ whereas for the NW-SE axe canyon, it was $22 \%$.

A recent work of Abolelata and Sodoudi [75] aimed to reducing energy consumption by mitigating UHI in Cairo through different urban tree coverage scenarios. Comparing the baseline scenario and alternative scenarios (30\% trees, $50 \%$ trees and $30 \%$ trees $+70 \%$ grass) revealed $3 \mathrm{~K}$ cooler thermal comfort for the $50 \%$ trees scenario, but none of the scenarios fulfilled reductions in buildings energy consumption, as the geometrical adjustments didn't took place; the street orientation, the aspect ratio and other geometry parameters play an crucial role and have to be considered.

In another study by the same authors [76], two case studies in Cairo were simulated using ENVI-met; Imbaba-65\% urban density, and officers residences in the Elsalam district-23\% urban density. A percent of $30 \%$ trees, $50 \%$ trees and $70 \%$ grass scenarios were applied to investigate their energy consumption implication. The study revealed a reduction of $0.2-0.4 \mathrm{~K}$ to the daily air temperature in very high density Imbaba site, while increasing air temperature by $3 \mathrm{~K}$ in low density site owed to the increased humidity.

\subsection{The Green and Blue Infra}

The GreenSect, Green cooling cover over a city tranSect, is a passive urban planning strategy that considers a bio-meteorological green structure along the urban transect [77] from the rural reserve to urban core [78]. Pedestrian walking speed of about $4 \mathrm{~km} / \mathrm{h}$ is used to calculate the distances between each GreenSect cooling node using the 5-15 min maximum walking distance between neighborhood sides. Within a city GreenSect, Urban trees lines play an essential element modifying urban microclimate conditions of both new and existing developments especially in arid environments. Furthermore, urban trees possess visual, aesthetical, and psychological adaptation [79], as well as, noise reduction, and air filtering effects [80-82]. Moreover, the main thermal performance advantages of trees are attributed to the radiation interception and evapotranspiration effects that modifies the heat budget of surrounding air and surfaces $[26,44,63,83,84]$. However, that is why adaptation to climate change considers vegetation as major applications to reducing heat stresses, energy consumption and in turn carbon emissions $[18,52,85]$. In completion to the green infrastructure, Ayad et al. [86] used a coupled simulations workflow for three combined simulation models; microclimate, building energy and climate change. The author investigated the effect of both green and blue infrastructure (GBI) in present and future climates through the climate change projections of the Fifth Assessment Report (AR5) published by IPCC around Al-Mahmoudya channel in Alexandria, Egypt. ENVI-met, Design Builder and Weather Shift were the methods of the later study which revealed that using BI alone increased energy use efficiency by $(8.12 \%)$ followed by GBI $(6.73 \%)$ and GI $(4.78 \%)$. Increasing the canopy green coverage percentage has a negligible impact on the energy savings. There is a potential of increased energy efficiency of $2.87 \%$ appear by using water cover. The usage of GBI, increase the energy efficiency by about $5.14 \%$. 


\section{Methods of Microclimate Research in the Egyptian Context}

\subsection{ENVI-Met and Field Measurements}

Evaluation of urban design environmental effects is crucial at the early design stages of urban environment. This approach has been presented by Bruse [68,87], who developed and used ENVI-met for assessing thermal effects in many cases. It should be noted that bigger urban sites necessitate more details when using the numerical methods to differentiate between master plans. In this concern, ENVI-met as a 3D prognostic model is the only tool that assesses human thermal comfort in terms of PMV, the Physiological Equivalent Temperature (PET) [88] and Universal Thermal Climate Index (UTCI), and predict all meteorological and soil-building-plant-air physical properties [26-28,59]. The meteorological and physical data entry of the design day (simulated day) can be derived for ENVI-met from the weather analysis tool of ECOTECT [89], field measurements and from calculations. In completion to the application of ENVI-met, either Energy Plus or Design Builder can be used to couple the outputs with the indoor environment, energy and carbon emission simulations $[3,60,90]$.

ENVI-met is validated by many research studies and proven reliability for many meteorological parameters, [3,91,92]. It has been validated for solar radiation in the work of Toudert [93], and for the RH [59]. In addition, ENVI-met has been combined with field measurements to represent Egyptian urban trees in the vegetation database through the measurements of LAI and Albedo using LAI2200c plant canopy analyzer [70] and the use of two back to back CMP21 high temperature pyranometer manufactured by Kipp \& Zonnen [71] as albedometer. In the study of Fahmy et al., to develop UDCM [44], ENVI-met has been validated against both air temperature and the mean radiant temperature. This took place by comparing field measurements and ENVI-met receptor point output at the same field grid, using the Onset HOBO-U30 portable weather station [94] to measure $T_{a}, R H$, and V, while the Heat Stress WBGT globe thermometer measurements [95-98] were used to measure the radiant temperature at the same grid of the receptor placed in ENVI-met Spaces modeling tool. The comparisons indicate statistical confidence both in the ENVI-met meteorological results as well as in the Ladybug tools workflow that can be also applied to calculate PET [99]. In a further improvement for urban simulations, Grasshopper has been developed in association with Ladybug Tools to generate the INX model area file of ENVI-met simulations after reading all model and sub-models data bases including the vegetation but such a valuable connection hasn't been applied in the Egyptian context yet. As a programming environment, Grasshopper is capable of running integrated and compact graphical algorithmic editor for the 3D tool [100], Rhinoceros generates complex 3D models from simple shapes and curves [101] hence is considered a forward step towards sophisticated urban simulations [102].

\subsection{Assessing Energy Efficiency through Coupling ENVI-Met and Design-Builder}

Since the early landmark contributions of Olgyay [103,104], Fanger [105] and Givoni [106,107], the assessment of either the single building scale or the urban environment scale has emerged rapidly due to the fast urbanization and complex interactions between the atmospheric environment and the built environment. However, both scales of fabric; building and urban have been mostly dealt with separately from each other owed to the complexities of field measurements and the incapability of simulation packages to do both jobs in one tool.

Consequently, coupling outdoor-indoor simulation methodology using ENVI-met and the CAD interface, Design Builder of the EnergyPlus tool [108], has been used in the Egyptian context starting from the work of Fahmy et al., [50]. The latter study investigated the effect of urban trees on both pedestrian and occupant thermal comfort in Cairo and concluded a positive effect of trees in terms of PMV reductions. The methodology has been applied again $[60,109]$ to study the influence of greenery (trees, green roofs and walls) in two different climatic zones of Egypt on the energy efficiency in present and under climate change scenarios (2020, 2050 and 2080) using the tool that applied the 4th assessment report morphing methodology of IPCC representative climate pathways, CCWorldWeatherGen [110]. The study revealed that, "in comparison to their un-adapted cases, the least energy efficiency result for 
whole site was $10.0 \%$ corresponding to $23.8 \%$ cost saving at 2080 in case two whereas the maximum was $21.3 \%$ corresponding to $35.7 \%$ cost savings at present day. Summing energy savings until the end of century, case one payback period was 20 years (in 2037) and case two was 15 years (in 2032)".

A further step using the same methodology is applied in the work of Ayad et al. [111] to study the green and blue infrastructure effects on the energy efficiency in Alexandria in present and under climate change scenarios of the $5^{\text {th }}$ assessment report of IPCC [112] using the weather shift tool [113]. Eventually, Abolelata and Sodoudi $[75,76]$ used the same methodology to mitigate UHI in Cairo using trees.

The methodology depends on transferring the meteorological output of ENVI-met urban simulations to modify the weather files used in Design Builder to account for urban details that indoor simulations do not consider such as the evapotranspiration of trees as an example not to mention. The methodology proved reliable outputs and therefore can be considered the second movement of using simulation assessment tools in the process of sustainable design of built environments. Another further step investigates the differences between using the 2003 ETMY data sets in comparison to 2017 data sets but still needs to be related to urban scale rather than only for buildings to consider the urban context effects, [114].

\section{Urban Microclimate Research Gaps in Egypt}

\subsection{The Need for an Urban Microclimate Design Model}

In order to mitigate the lack of connection between climate knowledge and real practice, the UDCM model has been developed after a numerical and optimization workflow to predict land use budget at the early urban design stages while sketching design alternatives on a pedestrian thermal comfort basis as holistic parameter that summarizes built environment and meteorological effects. However, there still a need to enhance such design model approaches through the increased cases that build the sample regression and optimization upon. Furthermore, UDCM has been designed for specific sections within transect of Cairo as mid-latitude site of Egypt not for all the eight climatic regions of the country. On the other hand, despite such models facilitates, speeds the urban form design process and gives passive basis for the urban form which will be a useful tool for urban designers; it needs more insights on the limitations of such models towards a promising code for sustainable neighborhood design.

\subsection{Neighborhood as a Sustainable Town Planning Unit in Egypt}

Neighborhood represents a significant interest to the built environment stakeholders as a crucial planning unit. However, Egyptian governorates are very crowded, overpopulated, and possess a great amount of GHG emissions and heat island effects. Therefore, the government has taken into responsibility to plan new communities. Hence, it is important to construct these communities on a sustainable strategies basis to mitigate the aforementioned impacts. There are three main milestones that can improve the sustainability in the neighborhood scale, which are: (1) heat island mitigation, (2) vegetation and thermal performance, and (3) pavements and microclimates. Vegetation can play a major role in improving the microclimate in several aspects such as acoustics, pollution alleviation, aesthetic values, social issues, and energy saving in buildings achieved by less cooling or heating loads. Moreover, in typical city, pavements cover about $20 \%-40 \%$ of the urban fabric that consist of asphalt and concrete surfaces that possesses high surface temperatures during summer and contribute to the development of urban heat island. Utilizing cool pavements are favored for their increased solar reflectivity, thermal emissivity, and their ability to promote water evaporation. However, reflective pavements are more advantageous because of their ability to reduce the surface and ambient temperatures, decrease $\mathrm{CO}_{2}$ emissions, reduce smog, increase the illumination and increase durability. 


\subsection{Present Housing Typologies; with or against the Climate Responsive Neighborhood Design?}

Due to increase in population that are expected to live in urban areas, as well as, the increase in air temperature because of the changing climate [115], it is crucial to establish an adaptive and responsive thermally efficient built environment by means of implementing passive design strategies at both building and urban scales. At the urban scale, reducing energy consumption in buildings and alleviating the urban canyon temperature is an integration of several passive design strategies such as trees $[3,59,60,116]$, green roofs $[69,73,117,118]$, green walls, and the fabric of local micro-climate scale [44,119-121]. Based on these studies, the energy consumption of the whole examined urban forms and the housing typologies is proposed to be passively reduced through design, and the remaining energy demand can be met by renewable energy systems.

Egypt, as a hot arid zone country, has a unique climate that is favored by high solar energy potential. Therefore, planning and designing urban communities to be compatible with this climatic condition is crucial. There are 2.2 million residential units constructed in the new cities in Egypt. The typologies and character of these housing projects replicated in spite of the variation in geographical locations and corresponding climate. At the urban planning level, most of these constructed communities formed from repetitive freestanding models of apartment blocks. The drawbacks of these urban arrangements are the lack of consideration to the energy efficiency and the mitigating of the microclimate conditions, especially during the hot summer, which can be alleviated by considering; the orientation of the buildings, the outdoor space proportions, the streets and path ways aspect ratio should be logically related to shading and wind speed characteristics, Albedo of the ground-level materials, configuration of greenery. On the other hand, at the building scale or housing typology, energy efficiency was not considered in these constructed buildings which rely on the thickness of the building envelope, the window to wall ratio, roof materials. Therefore, the indoor and outdoor climate are negatively affected in these new communities, making the residents rely on the using air conditioning to achieve their thermal comfort, and making them not prefer to walk when they are outdoor. In which these activity profile of residents increases the energy consumption, depletion of resources, increasing $\mathrm{CO}_{2}$ emissions and GHG. Hence, well considering the housing typologies and the urban microclimate became substantial aspect, not any more a matter of achieving prosperity and welfare in living conditions.

\subsection{Limitations of Urban Microclimate Research Methods}

\subsubsection{Limitations of Simulation Tools}

While ENVI-met is regarded as a reliable and validated microclimate simulation tool at early urban design stages, it doesn't support bigger climate scales' simulations with regard to the city and regional scales which can be generated through field measurements in order to either project them in future with consideration to climate change scenarios, downscale them in order to generate recent weather files or couple different climate scales models' generated by them, the work of Li, $\mathrm{H}$. , et al., is just an example not to mention [122,123]. On the other hand, microclimate simulation tools have limitations with regard to computational optimization of urban form designs according to environmental conditions. Even after implementing most of its new options in the Grasshopper canvas through Dragonfly plugin [124] to generate required model and simulation files. This connection has two main advantages: (1) significantly reduces time required for modelling and simulation setup processes, especially when investigating several microclimate models. (2) facilitates the ability to import complex and non-traditional building 3D shapes into ENVI-met spaces. However, retrieving simulated readings and generating microclimate maps are executed manually after finishing the simulations. Hence, parametric microclimate and outdoor comfort simulation tools are regarded as the most suitable alternative for urban form optimization process. Yet these tools have their own shortcomings regarding computational power, user experience and the credibility of the simulation outputs. 
Regardless the persistent advancements of Ladybug Tools [125], for instance, a single integrated parametric workflow that generates outdoor thermal comfort and microclimate maps from basic inputs - such as meteorological data and model's geometry and materials - has yet come to existence. The workflow introduced by Mackey et al. [126] was validated against ENVI-met results and in-situ measurements for a tree-less actual site in Cairo, Egypt by Elwy et al. [99], incorporates different effectual factors on outdoor thermal comfort that were calculated separately. Location specific wind speed, radiant temperature, and accounting for Urban Heat island (UHI) effect using Urban Weather Generator (UWG) [127] are all separate applications for different tools, which are combined into a simulation workflow by a manual and sequential technique [128].

Another limitation for using such tools is that they do not account for the interaction between vegetation and microclimate, in terms of their evapotranspiration effect on air temperature $\left(T_{a}\right)$ and air relative humidity $(\mathrm{RH})$. Trees' canopies could nevertheless be modeled using these tools as shading objects, with a transparency factor according to the percentage of reduction of solar radiation that corresponds to each type of tree. UWG, and its connection tool with Grasshopper, Dragonfly, can estimate vegetation effect on UHI while morphing a rural weather file into an urban one. But this is inconvenient on an urban micro-scale, since it does not provide location specific Ta and RH variations depending on the effect zones of vegetation or water bodies. On the contrary, this approach produces a single value throughout the whole site to investigate, which are obtained from the resultant weather file. Moreover, taking into account that most of new towns nationwide are deficient in meteorological data. Hereafter, UHI morphing an interpolated weather file using Meteonorm software [129] while providing the proposed location as a city would give a deceptive weather data file.

Refraining from the shadow impact of trees on the ground and adjacent buildings' facades, and their wind blockage capability using CFD analyses, some recent software innovations account for vegetation and water bodies much effectively. For example, to demonstrate the significance of evapotranspiration in microclimate simulations, and under the condition of no air movement (wind speed $(U)=0 \mathrm{~m} / \mathrm{s}$ ), Nielsen [130] realized an average reduction in UTCI values of about $3.7^{\circ} \mathrm{C}$ by comparing the same case study in Abu Dhabi, UAE, with and without including evapotranspiration effect from trees and water. The study was mostly centered on developing an alternative simulation method to be utilized along with Ladybug Tools to create UTCI thermal comfort maps, yet, still lacks to validate its results. On the other hand, Manickathan et al. [131] used OpenFOAM [132] CFD model to investigate the cooling effect of trees, in which the influence of air movement on evapotranspiration-based cooling is highlighted. According to the study, the cooling effect reached its maximum at low wind speeds $(U<1$ $\mathrm{m} / \mathrm{s}$ ), and it almost diminished as U reach high values. The case study was implemented in the city of Zurich, Switzerland, which climate is classified according to Köppen-Geiger [133] as Warm-Fully Humid. Therefore, this approach needs to be calibrated at Egypt's Hot-Arid climate.

Furthermore, another recently developed CFD tool of OpenFOAM that predicts outdoor thermal comfort is the uhiSolver [134]. Developers of this tool introduced it as a set of adjustments that were applied to the existing CFD solver to comprise different physical features for outdoor thermal comfort prediction. Radiative heat fluxes, sun and shadow tracking, evaporative cooling and humidity effect form vegetation, green structures and water bodies are some of the added capabilities of the CFD solver [135]. Being run under the platform of OpenFOAM might give it the potential to be connected via Grasshopper canvas. Additionally, these tools are desirable to come into practice during the early environmental urban form design stages in Egypt, in order to identify its suitability for Egyptian context and figure out their application benefits and shortcomings.

\subsubsection{Limitations of Field Measurement Methods}

Despite that some few studies took place in the urban climate research in the Egyptian context using field measurements [10], there still a lack in the remote sensing and airborne methods which can be dedicated to thermography, laser scanning and meteorological measurements. It can be argued that funding such methods is an obstacle in spite of the increased knowledge and availability of 
importing drones and surveying planes (airborne methods) to Egypt. In future investigations, such approaches can be applied in the UHI research [136], scanning and retrofitting already existing urban forms towards concluding implications for the new urban developments in Egypt.

\subsection{Vegetation in the Energy Codes and Green Rating Systems}

Trees Canopies ground Shade coverage (TCS) hasn't been considered as a vital element in the Egyptian building energy code [137] nor in green pyramid rating system [138], the GPRS, or any green rating system. Except for the Singapore Green Mark Rating System, trees are considered but only empirically through a greenery provision term considering the 3D volume of trees in an urban space. To consider such, and to calculate green rating system's credit points and determine the weights of urban trees' ground coverage effects on microclimates which in turn affect indoor environments, a database for the modeling parameters of famous Egyptian urban trees' species have to be established. Such database in terms of LAI and Albedo measurements has to be followed by numerical modeling and simulation for the thermal effects of each tree for the sake of weighing the accreditation of TCS points according to the expected microclimatic amelioration that a tree shading and evapotranspiration can do rather than empirical. The same concept applies to introduce a new chapter in the Egyptian buildings energy code. However, such improvements to the codes and rating systems needs a rigorous research fund dedicated towards supporting the required field measurements devices by urban environmental measurements' labs.

\subsection{The Need to Customize a Hot Arid Thermal Comfort Index}

The Egyptian studies used the global thermal indices to assess the thermal performance whether for indoor or outdoor performance such as PET and PMV. Despite, these indices are well documented and include thermo-physiological and meteorological parameters; they limit values thought for special climatic conditions and might not express human comfort for other climatic regions especially with respect to hot arid region as Egypt. Therefore, it should be investigated in term of its applicability in the Egyptian climate context. Such investigations are important to identify regional particularities, and it can be considered an approach to have an adaptive thermal comfort index based on human sensation vote using questionnaire even for the eight climatic zones of the Egyptian map. The later approach has been investigated similarly in the project RUROS [139], where the psychological adaptation played an important role in the formulation of a thermal comfort index in some European cities and new concepts such as stimulating pedestrian to accept higher rates of thermal stresses has been introduced.

\subsection{Integrating Multidisciplinary Sustainabile Design Experts Towards the 5th Generation of Egyptian Cities}

Gathering the research line that has been presented through Sections 3-5 of this article for the urban built environment elements in the Egyptian context; fabric, network and vegetation, this section presents a vision for a new ERA of Egyptian housing through the integration of both passive architecture and passive urban design scales that conserves energy, and the triple core mission of ERA can be completed by proposing a renewable system that might be applied both on building envelope and on-site land use. It worth mentioning that ERA is a two parts proposed research project collaboration between multidisciplinary experts and it has been designed in three steps for the sake of a new generation of Egyptian energy efficient housing and resilient cities; (1) It starts in the urban form were a geo-informatics drone assisted surveys and auditing will take place for thermal imagery and meteorological measurements to be used for energy retrofitting of existing housing. (2) It suggest the clustered urban form for medium population (medium and social class housing) which is built on prior findings illustrated in the previous sections of this article; it identified the neighborhood clustered urban form as an appropriate residential archetype. However, a parametric optimization should be used to generate the most suitable building-courtyard relation of cluster geometry according to each climatic zone configuration on the Egyptian map which is the core of the new ERA housing typologies of the project. (3) It focuses on the residential building and its passive cooling techniques according the 
Egyptian code for energy efficiency. A whole-building energy simulation will be conducted depending on the urban simulations' outcomes from the first step using coupled simulation methodology. (4) The fourth step incorporates the possible solutions for introducing PV systems into the building envelope as an integrated building active-passive design. ERA has a tripling evaluation methodology (TEM) that explores the impact of neighborhood configurations have on urban microclimate conditions, and in turn on urban housing energy efficiency, considering also the improvements of urban form that may affect the PV/envelope system. ERA suggests considering the climate change scenarios to adapt its generated housing for future. ERA project proposal is still under development and didn't have results yet.

Figures 6-9 summarize and show the connection between the methods reviewed in this article and how ERA can introduce what can be called the 5th generation of Egyptian sustainable cities knowing that the 1st generation of new cities developments started with the 15th of May and 10th of October cities five decades ago [140].

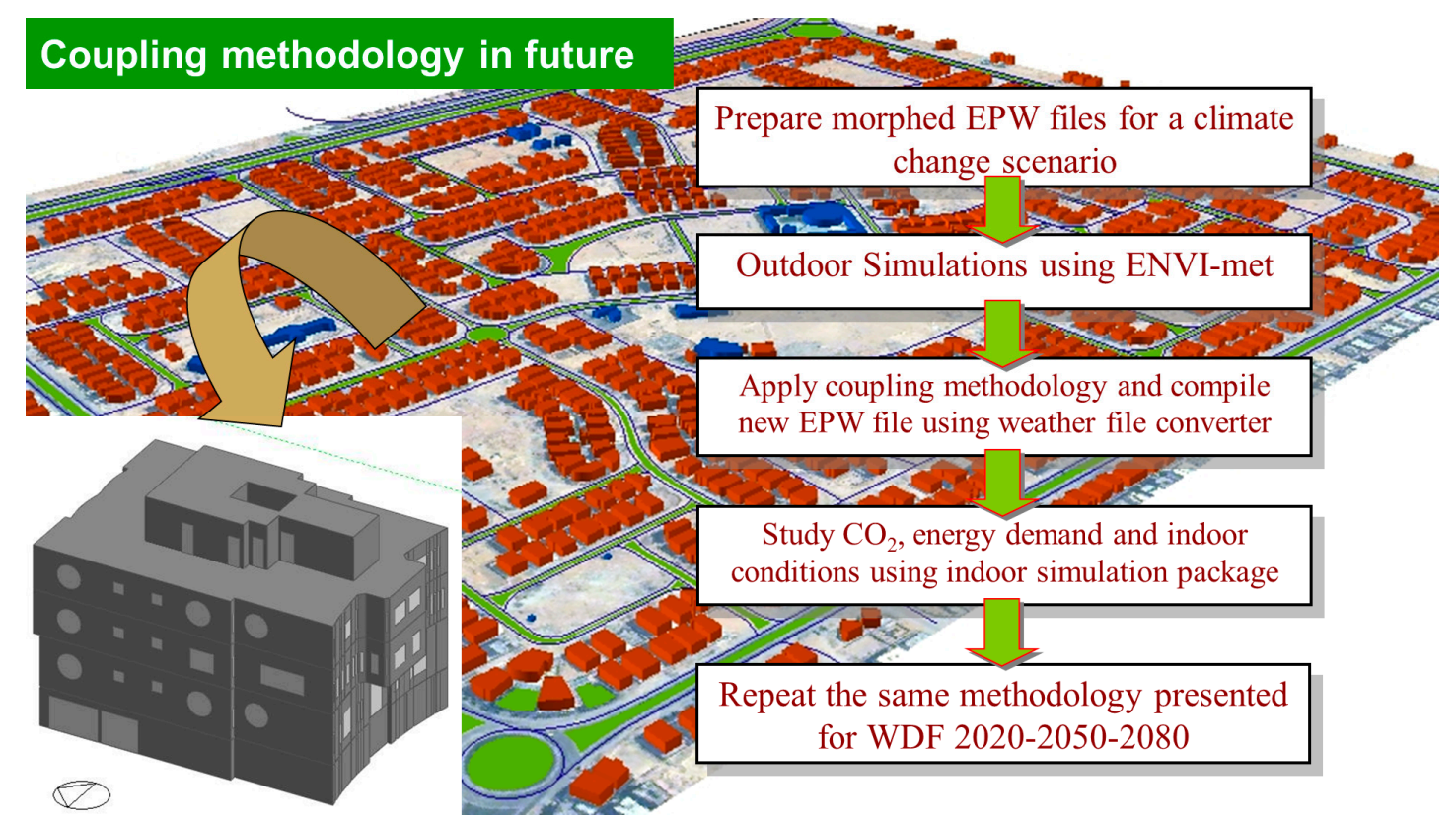

Figure 6. The coupled simulation methodology in present and future as a baseline for ERA Tripling Evaluation Methodology, TEM, modified after [37].

The connection between the aforementioned methods and the 5th generation can be explained as the original coupling urban-building simulation methodology (Figure 6) has been modified by adding grasshopper optimization of the clustered urban form for different climate zones (Figure 7), then the urban-building dimensions has been extended to include the third pillar of ERA project, energy, (Figure 8). Finally, the dominant concerns of ERA pillars have to be evaluated through the tripling methodology (Figure 9).

It woth mentioning that in the 1970s, Cairo plans were drawn up with satellite cities around it. The construction of 10th of Ramadan city, an industrial city, was the first generation experimental new city to take place. 2nd generation examples include Sheikh Zayed City, whereas New Cairo represents the 3rd generation which moved away from the working-class cities to form new communities for the privileged high income class, [140]. The new cities housing strategy remained vehicular oriented urban development that applies typical repetitive designs in different Egyptian regions discarding the different climate conditions. Today the New Urban Communities Authority (NUCA) has promising plans for the $4^{\text {th }}$ generation but kept new cities such as New Mansoura and New Alamain without in-depth responsive design to climate despite the different climate zones on the map, Figure 10. 


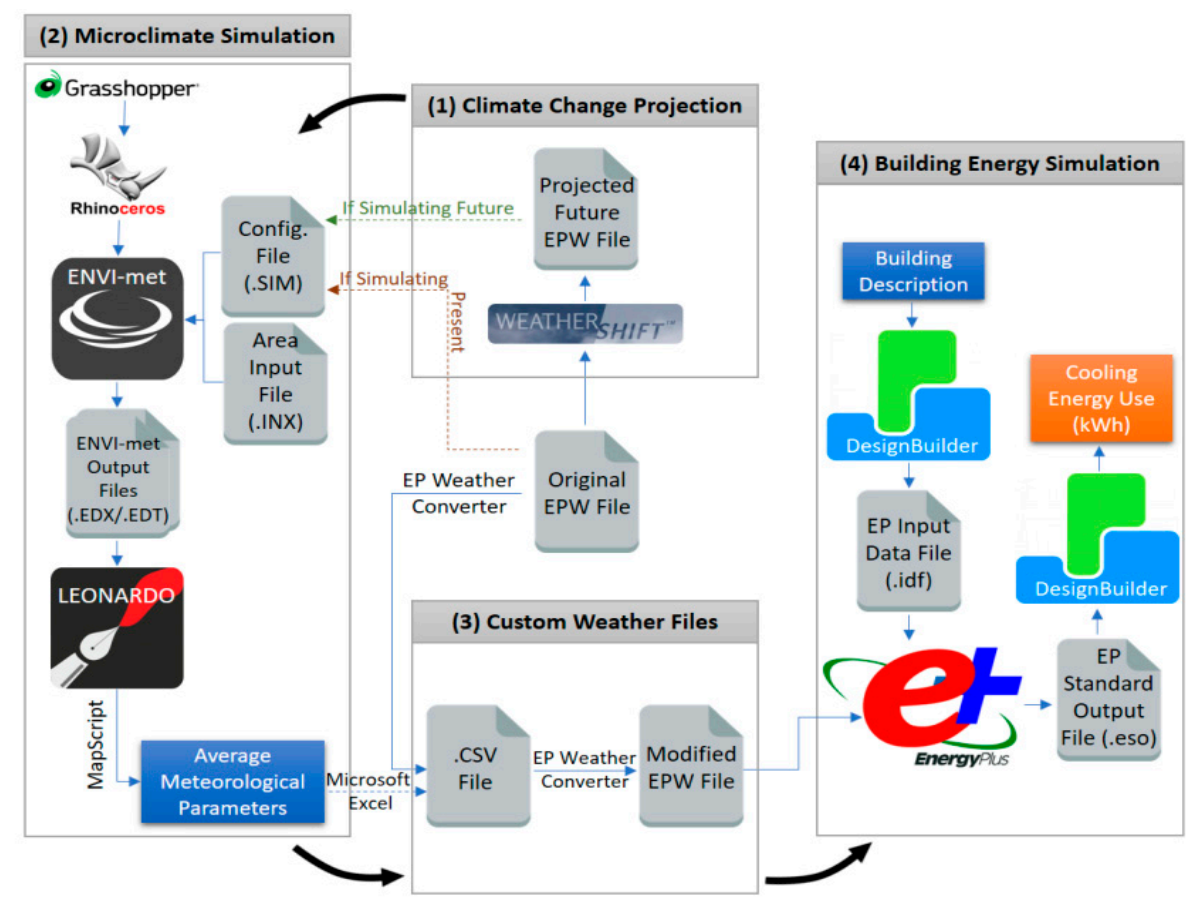

Figure 7. Software cycling of ERA core starts with modifying the original coupled urban-building simulation with grasshopper parametric optimizations of the urban cluster baseline for the different climatic zones on the Egyptian map, modified after $[60,86]$.

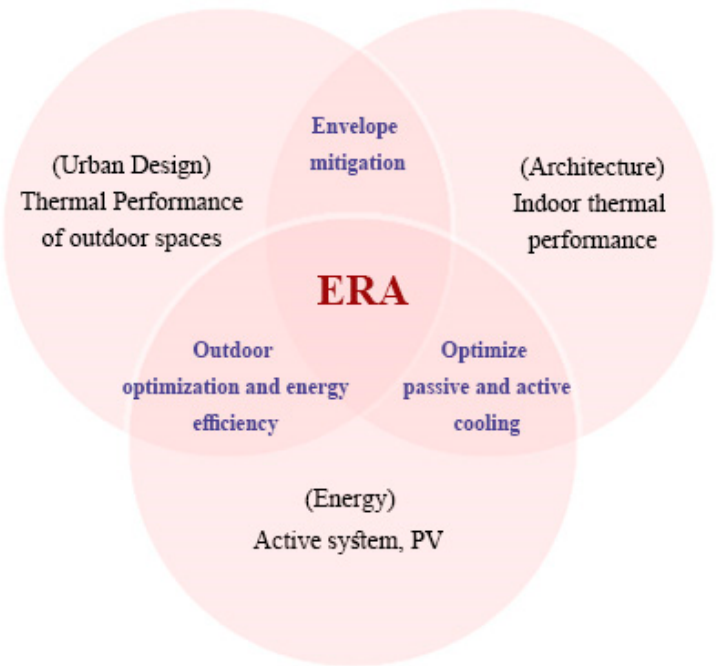

Figure 8. ERA Tripling Evaluation Methodology, TEM.

Furthermore, the point is not only a physical design of the urban form, the application of such fabric that generates the linear/clustered semi-attached housing typologies has to be accompanied with a development in the construction legislations that necessitates the urban designer to stop at the step of planning a residential zones within neighborhoods rather than designing the housing linear/clustered housing itself. The fixed concepts of executive plans that oblige setbacks for a residential building from the four sides of lots which generates the dot housing patterns have to be improved to an urban microclimate-passive housing linear/clustered oriented concept. In addition, this facilitates Building Integrated PV system, BIPV in which the PV panels are adapted and integrated with building envelope architecture form, [141]. 


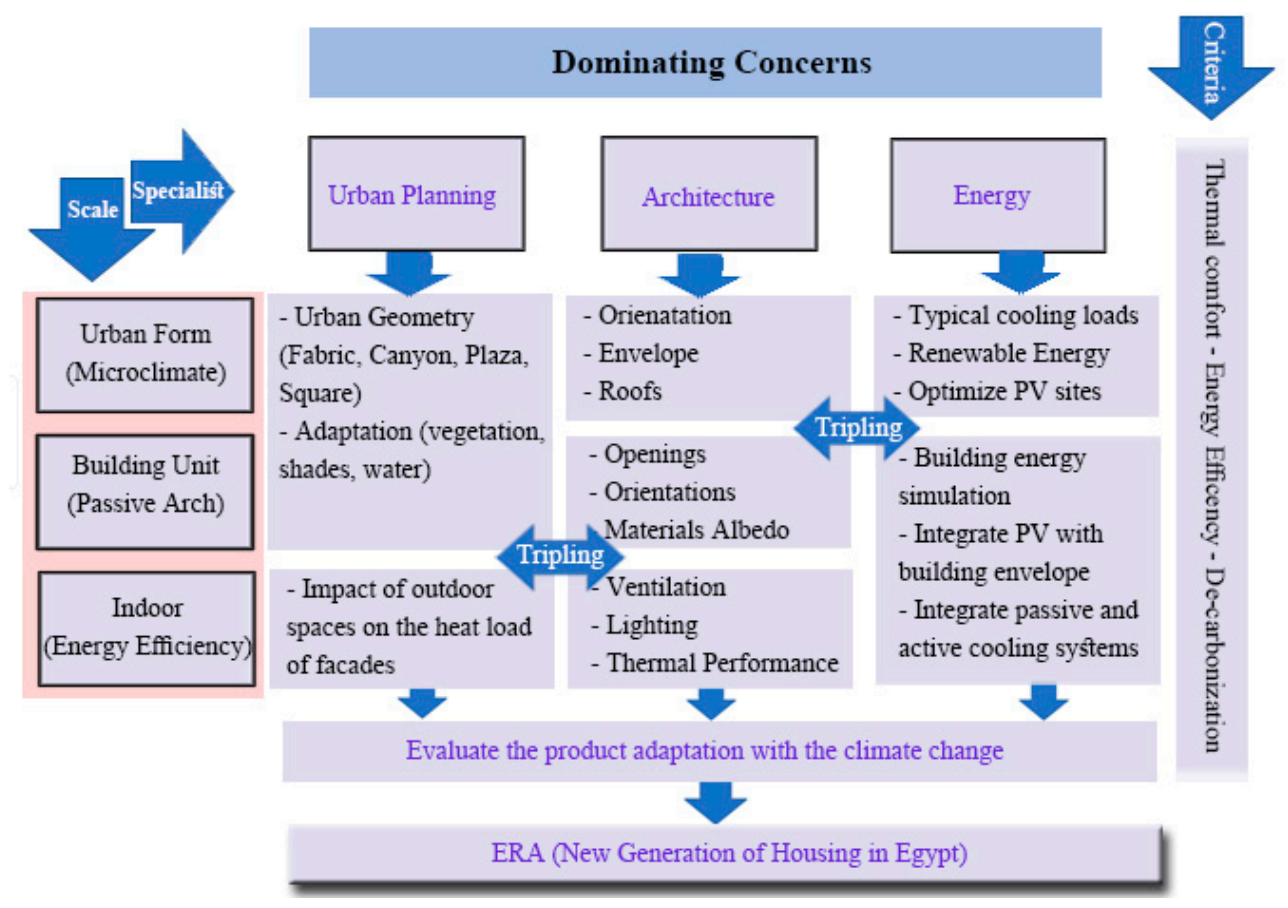

Figure 9. ERA dominating concerns that have to be evaluated by the Tripling Evaluation Methodology, TEM, to integrate the Urban-Building-Renewables dimensions, UBR.

Therefore, a call for the 5th generation of Egyptian cities can be raised from this review article based on the integration of an Urban microclimate basis to generate linear/clustered fabric, Building passive design that generate envelope, along with Renewables, such integration can be abbreviated as UBR., Furthermore, despite the fact the two examples presented in Figure 11a,b are from different climate regions and conditions, they still represent a successful example for 2 dimensions of UBR, housing environmental and BIPV design, which is not part of the housing typologies design process in Egypt. Moreover, it gives a positive indication for how UBR can be disseminated over the different eight climate zones of Egypt. On the other hand; Figure 12a,b represent examples of the newly constructed housing in New Asyut and 10th of Ramadan cities as part of the efforts of the national mega project of social class that ERA target to improve. It is proposed that UBR considers the microclimatic basis to guide optimizing the geometrical adjustments of urban form design practice and generating specific clustered housing typology for each climate zone rather than the common typical multi story apartment buildings. In this concern, the majority of the inhabited locations in Egypt has climate that is either hot and humid or hot and arid. Moreover, most of the regions in Egypt are favored by high solar energy potential. Therefore, as the population has grown beyond the 100 million; planning and designing urban communities to be compatible with these climatic conditions become crucial. The legislation has to comply with the requirements of the 21st century and its major environmental challenge, climate change, not only to construct to accommodate, in another word; a city sustainable design code has to emerge having UBR and TEM as a core. From this standing point, improvements of energy efficiency and de-carbonization of housing environment will contribute to the submission of the second National Determinant Contribution, NDC of Egypt commitments to the United Nations Framework Convention on Climate Change, UNFCCC, and Paris Agreement and facilitate Egypt sustainable development vision 2030. The UNFCCC and Paris agreement are a mankind contributions to the global environmental safety of human future on earth through which, both developed countries (Annex I countries of UNFCCC) and developing countries (Annex II countries of UNFCCC) can fulfill this safety by their de-carbonization projects either in terms of mitigation or adaptation plans [142,143]. 


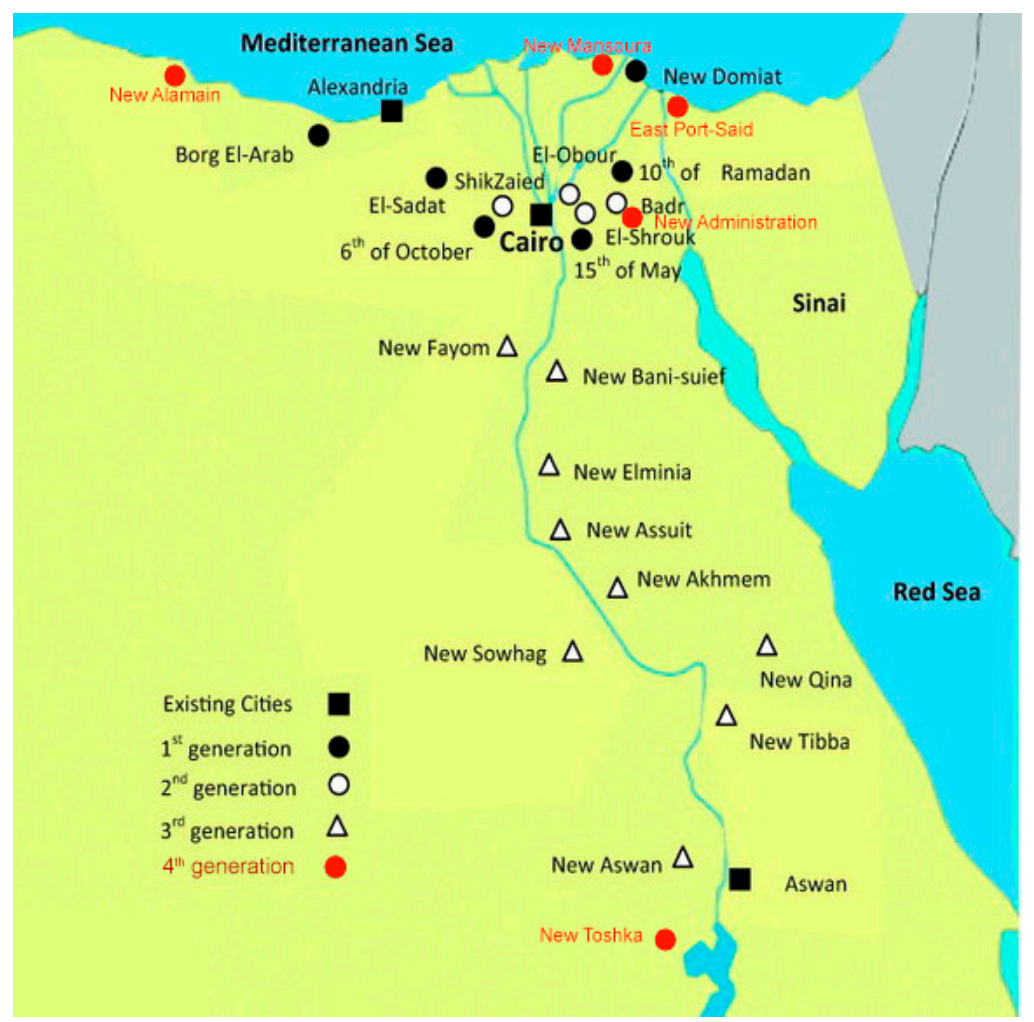

(a)

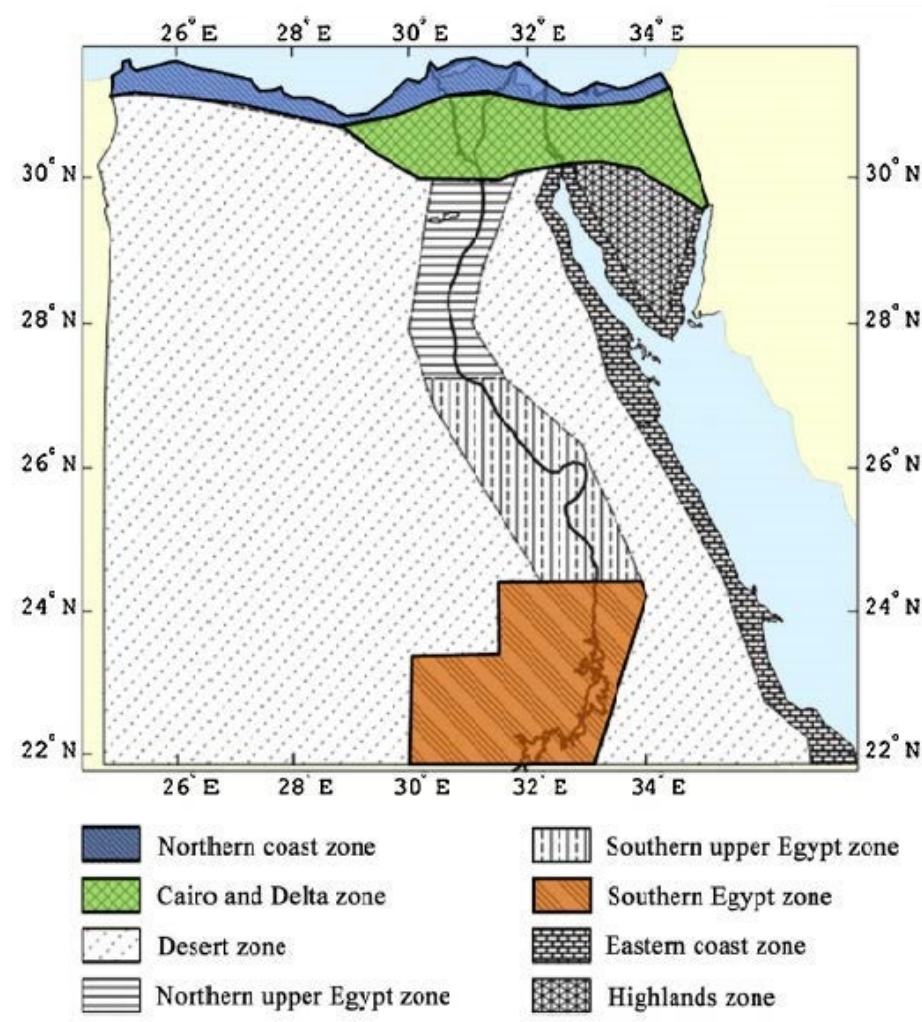

(b)

Figure 10. (a) Generations of New Cities in Egypt since 1970s, modified after (Hegazy and Moustafa 2013) [140]. (b) different climatic zones in Egypt, [137], (North is up and scale is to fit). 


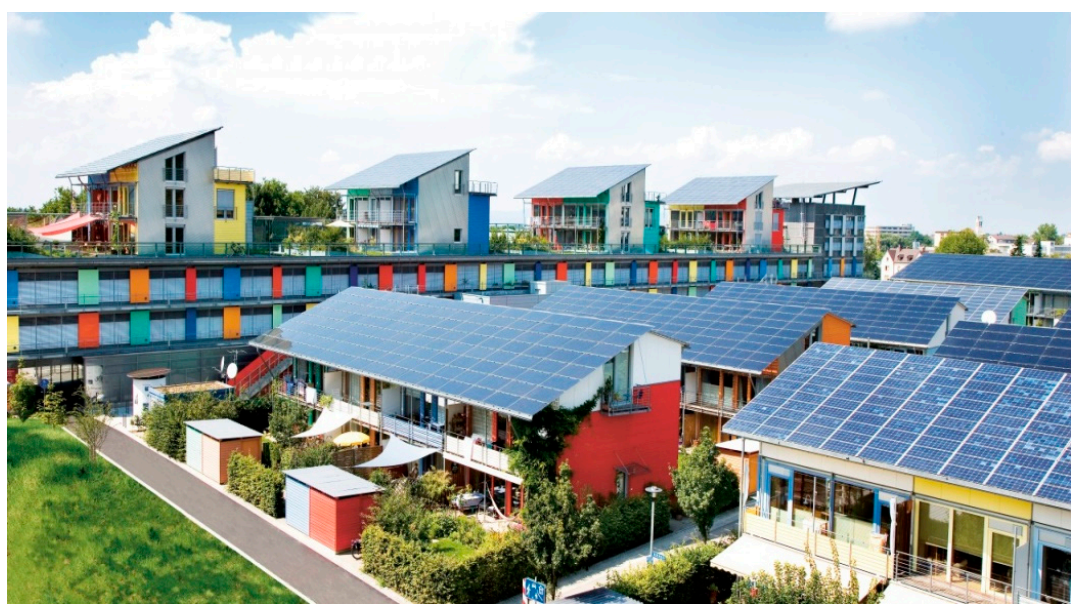

(a)

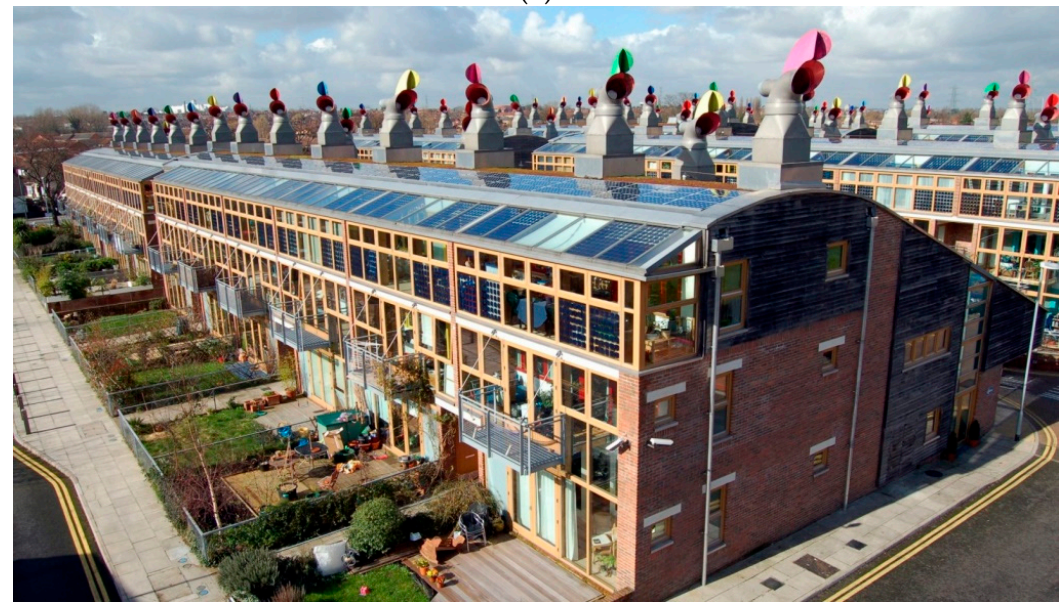

(b)

Figure 11. (a) The energy plus solar housing settlement at Freiburg by ROLF DISCH, Germany, [144]. (b) Beddington Zero Energy Development (BedZED), London, UK, [145].

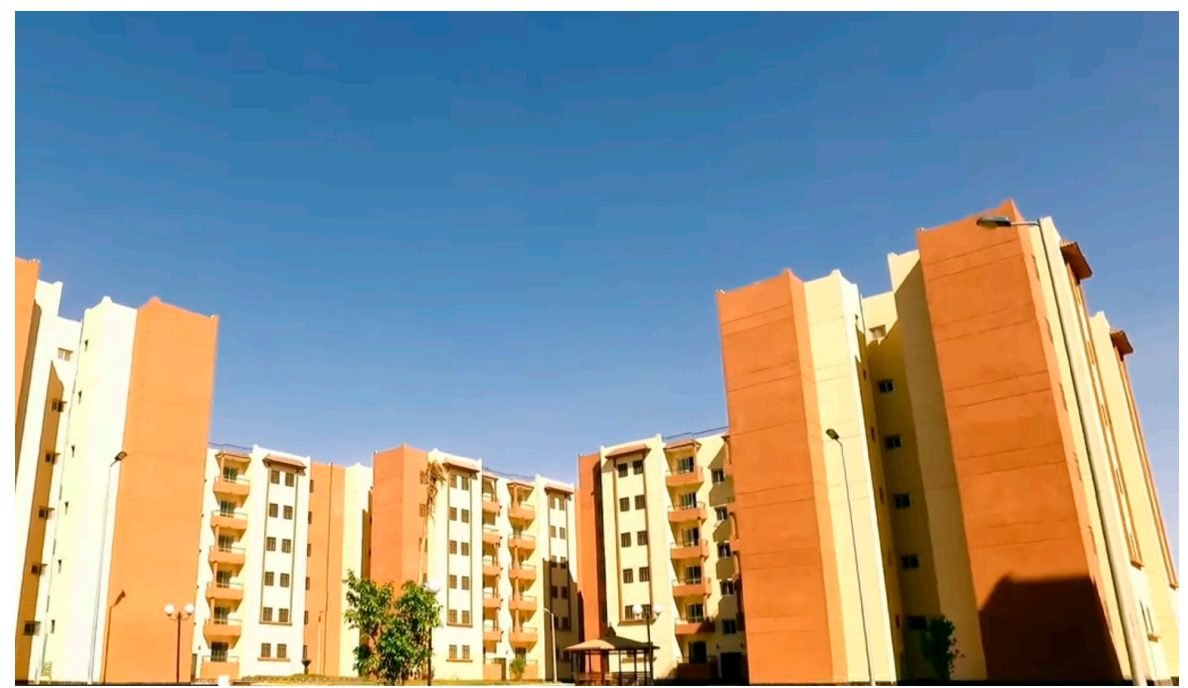

(a)

Figure 12. Cont. 


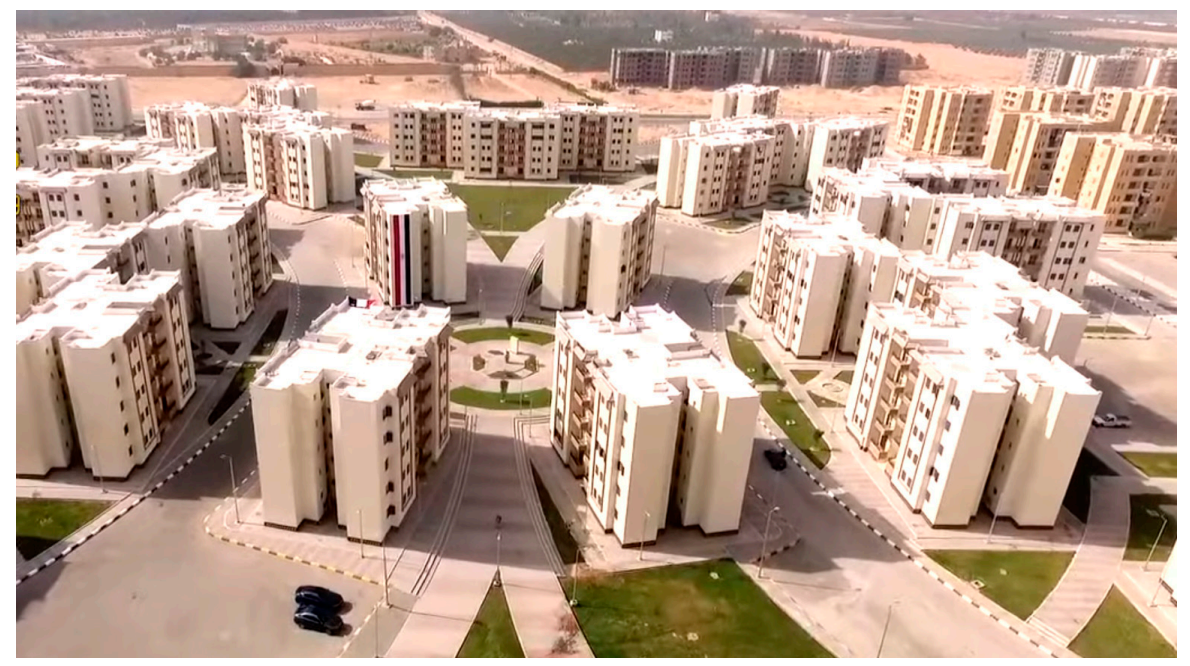

(b)

Figure 12. (a) Social housing in New Asyiut, the same typology as in 12b [146]. (b) Social housing in 10th of Ramadan city [146].

The above mentioned vision needs an integrated multidisciplinary specialists' team formation in order to undergo such ambitious project, there is a lack of an Egyptian platform or a hub that initiates research collaboration and uses the resources of the academia and industry rigorously in this area of research.

\section{Conclusions}

Due to the climate change and the rapidly growing population density in Egypt, it is necessary to pay more attention to the urban microclimate and its related housing strategies, typologies and research studies. Egyptian studies that addressed the urban microclimate and the thermal performance of outdoor spaces emerged early in the 21st century for the sake of filling the urban form design gap towards sustainable and resilient built environment; in this concern; a research line can be noticed out of those studies, but we need to ask what did they achieve? and what are the weaknesses? For that, this study highlighted and reviewed the Egyptian studies on the impact of urban pattern and adaptation strategies on outdoor thermal performance and on the indoor energy efficiency.

In last eleven years, despite the number of researches which specifically concentrate on assessing outdoor spaces are few, the Egyptian studies could achieve distinguished results in term of adjusting fabric, green infra and coupling the evaluation with introducing valuable recommendations. However, it is crucial to develop a comprehensive vision using this knowledge, focus on more details, locations and different climate zones of Egypt, and develop a framework stepping forward towards a national future vision and a new era of housing projects in Egypt to cope with the sustainability vision of Egypt 2030. Design implications can be summarized in terms of an optimized clustered urban fabric on a specific climate conditions basis along with selected vegetation species and adjusted trees ground coverage and spacing.

Furthermore, the study suggested the Tripling Evaluation Methodology (TEM) which represents an upgrade for the coupling simulation methodology that has been introduced in an Egyptian study. TEM methodology facilitates a comprehensive vision for the future studies and applications of Urban-Building-Renewables (UBR), dimensions towards a new era of energy efficient Egyptian housing typologies as part of a 5th generation of Egyptian sustainable cities. Such housing environment vision can contribute to both mitigation and adaptation plans though de-carbonization which in turn contribute to the submission of the second Egyptian NDC to UNFCCC. Moreover, a code for sustainable cities design having UBR and TEM as a core has to emerge. Nevertheless, no doubt that fund limits 
the usage of advanced field measurements such as remote sensing and airborne methods in urban climate research in compliance with simulation to validate and integrate the Egyptian multidisciplinary fields to contribute to sustainable urban development practices, a design code for it to adapt future communities for the adverse impacts of climate change.

Author Contributions: M.F.: Article's initiator, corresponding author, urban-building research line designer, contributor and initiator of the 5th generation of Egyptian sustainable cities idea and expression, PI of the two parts research project proposal ERA, gathering literature, defining methodology, contributing to several sections, writing and formatting of the manuscript, responses to and discussions with reviewers. S.M.: data gathering, contributing to several sections, writing and formatting of the article. I.E.: data gathering, contributing to several sections, writing and formatting of the article. H.M.: data gathering, defining methodology, contributing to several sections, writing and formatting of the article. All authors have read and agreed to the published version of the manuscript.

Funding: The Article Processing Charge of this manuscript was co-funded by the Environmental Measurements and Energy Efficiency Lab, Department of Architecture Engineering, Military Technical College and the research project "Adapting Sustainable Urban Planning to Local Climate Change in Egyptian New Towns (Case Study New Aswan)", grant number 23022". In the framework of the program German Egypt Research Fund "GERF4", funded by the Science and Technology Development Fund (STDF) in Egypt, and the Federal Ministry of Education and Research in Germany (BMBF).

Acknowledgments: The authors are expressing their appreciation for the Environmental Design Research Group and the Environmental Measurements and Energy Efficiency Lab (Founded by Mohammad Fahmy), Department of Architecture Engineering, Military Technical College for the support, efforts and the 2008-2019 research line discussed in this publication towards a new era of Egyptian housing environment. Appreciation also goes to the research project "Adapting Sustainable Urban Planning to Local Climate Change in Egyptian New Towns (Case Study New Aswan)" for the support to the efforts of publishing this article.

Conflicts of Interest: The authors declare no conflict of interest. The funders had no role in the design of the study; in the collection, analyses, or interpretation of data; in the writing of the manuscript, or in the decision to publish the results.

\section{References}

1. Jamei, E.; Rajagopalan, P.; Seyedmahmoudian, M.; Jamei, Y. Review on the impact of urban geometry and pedestrian level greening on outdoor thermal comfort. Renew. Sustain. Energy Rev. 2016, 54, 1002-1017. [CrossRef]

2. EEAA. Egypt 3rd National Communication Under the United Nations Framework Convention on Climate Change (UNFCCC); Egyptian Environmental Affairs Agency (EEAA): Cairo, Egypt, 2016.

3. Fahmy, M.; Mahdy, M.; El-Hady, H.; Yasser, I.; Abdelalim, M. Simulating the Carbon foot Print Reduction of an Arid Urban form Applying Canopy Layer Green Coverage under Climate Change Scenarios. Int. J. Appl. Eng. Res. 2017, 12, 12906-12913.

4. Fahmy, M. Numerical assessment for urban developments on a climate change basis; A case study in New Cairo, Egypt. In Proceedings of the 2nd International Conference on quality of life, Cairo, Egypt, 18-19 March 2012.

5. WHO; UNFCCC. Climate and Health Country Profile of Egypt; World Health Organization: Geneva, Switzerland, 2015.

6. Hassan, K. The Future Impacts of Climate Change on Egyptian Population; Egyptian Society for Migration Studies: Cairo, Egypt, 2009.

7. Shaharon, M.; Jalaludin, J. Thermal Comfort Assessment-A Study Toward Workers' Satisfaction in a Low Energy Office Building. Am. J. Appl. Sci. 2012, 9, 1037-1045.

8. Fahmy, M.; Sharples, S. Passive design for urban thermal comfort: a comparison between different urban forms in Cairo, Egypt. In Proceedings of the PLEA 2008 - 25th Conference on Passive and Low Energy Architecture, University Collage of Dublin, Dublin, UK, 22-24 October 2008.

9. Galal, O.M.; Mahmoud, H.; Sailor, D. Impact of evolving building morphology on microclimate in a hot arid climate. Sustain. Cities Soc. 2020, 54, 102011. [CrossRef]

10. Elnabawi, M.H.; Hamza, N. Behavioural Perspectives of Outdoor Thermal Comfort in Urban Areas: A Critical Review. Atmosphere 2019, 11, 51. [CrossRef]

11. Makumbe, P. Egypt Energy Efficiency Implementation: Energy Efficiency and Rooftop Solar PV Opportunities, Report Summary; World Bank Group: Washington, DC, USA, 2017. 
12. Hanna, B. Sustainable Energy Potential in the Egyptian Residential Sector. J. Environ. Sci. Eng. B 2013, 2, 374-382.

13. Abdallaha, L.; El-Shennawyb, T. Evaluation of CO2 emissions from electricity generation in Egypt: Present Status and Projections to 2030. In Proceedings of the First International Conference of Chemical, Energy and Environmnetal Engieering, ICCEEE, Alexandria, Egypt, 19-21 March 2019.

14. Harlan, S.L.; Brazel, A.J.; Prashad, L.; Stefanov, W.L.; Larsen, L. Neighborhood microclimates and vulnerability to heat stress. Soc. Sci. Med. 2006, 63, 2847-2863. [CrossRef]

15. Hassan, A.N.; Anthony, J.B.; Robert, C.B.J. Analysis of the Kuwait city urban heat island. Int. J. Climatol. 1990, 10, 401-405.

16. Balling, R.C.; Brazel, S.W. Time and Space Characteristics of the Phoenix Urban Heat Island. J. Ariz. Nev. Acad. Sci. 1987, 21, 75-81.

17. Rosenfeld, A.H.; Akbari, H.; Bretz, S.; Fishman, B.L.; Kurn, D.M.; Sailor, D.; Taha, H. Mitigation of urban heat islands: Materials, utility programs, updates. Energy Build. 1995, 22, 255-265. [CrossRef]

18. Huang, Y.J.; Akbari, H.; Taha, H.; Rosenfeld, A.H. The Potential of Vegetation in Reducing Summer Cooling Loads in Residential Buildings. J. Clim. Appl. Meteorol. 1987, 26, 1103-1116. [CrossRef]

19. Oke, T.R. Towards better scientific communication in urban climate. Theor. Appl. Climatol. 2006, 84, $179-190$. [CrossRef]

20. Oke, T.R. Towards a prescription for the greater use of climatic principles in settlement planning. Energy Build. 1984, 7, 1-10. [CrossRef]

21. Arnfield, A. Two Decades of Urban Climate Research: A review of Turbulence, Exchange of Energy, Water and the urban heat islands. Int. J. Climatol. 2003, 23, 1-26. [CrossRef]

22. Givoni, B. Climate Consideration in Urban and Building Design; Van Nostrand Reinhold: New York, NY, USA, 1998.

23. Burton, E. Measuring urban compactness in UK towns and cities. Environ. Plan. B Plan. Des. 2002, 29, 219-250. [CrossRef]

24. Burton, E. The compact city: Just or just compact? A preliminary analysis. Urban. Stud. 2000, 37, 1969-2006. [CrossRef]

25. Tablada, A.; De Troyer, F.; Blocken, B.; Carmeliet, J.; Verschure, H. On natural ventilation and thermal comfort in compact urban environments - the Old Havana case. Build. Environ. 2009, 44, 1943-1958. [CrossRef]

26. Ali-Toudert, F.; Mayer, H. Effects of asymmetry, galleries, overhanging facades and vegetation on thermal comfort in urban street canyons. Sol. Energy 2007, 81, 742-754. [CrossRef]

27. Ali-Toudert, F.; Mayer, H. Thermal comfort in an east-west oriented street canyon in Freiburg (Germany) under hot summer conditions. Theor. Appl. Climatol. 2007, 87, 223-237. [CrossRef]

28. Ali-Toudert, F.; Mayer, H. Numerical study on the effects of aspect ratio and orientation of an urban street canyon on outdoor thermal comfort in hot and dry climate. Build. Environ. 2006, 41, 94-108. [CrossRef]

29. Oke, T.R. Street Design and Urban Canopy Layer Climate. Energy Build. 1988, 11, 103-113. [CrossRef]

30. Nakamura, Y.; Oke, T.R. Wind, Temperature and Stability Conditions in an East-West Oriented Urban Canyon. Atmos. Environ. 1988, 22, 2691-2700. [CrossRef]

31. Shashua-Bar, L.; Hoffman, M.E. Quantitative evaluation of passive cooling of the UCL microclimate in hot regions in summer, case study: Urban streets and courtyards with trees. Build. Environ. 2004, 39, 1087-1099. [CrossRef]

32. Muhaisen, A.S. Shading simulation of the courtyard form in different climatic regions. Build. Environ. 2006, $41,1731-1741$.

33. Aldawoud, A.; Clark, R. Comparative analysis of energy performance between courtyard and atrium in buildings. Energy Build. 2008, 40, 209-214. [CrossRef]

34. Fahmy, M.; Sharples, S. On the development of an urban passive thermal comfort system in Cairo, Egypt. Build. Environ. 2009, 44, 1907-1916. [CrossRef]

35. Mahmoud, H. Effect of urban form on outdoor thermal comfort of governmental residential buildings: New aswan as a case study, Egypt. J. Eng. Sci. Assiut Univ. Fac. Eng. 2019, 47, 309-325.

36. Fahmy, M.; Sharples, S. The need for an urban climatology applied design model. Available online: http://www.urban-climate.org/IAUC028.pdf, (accessed on 20 February 2020).

37. Fahmy, M. Interactive Urban form Design of Local Climate Scale in Hot Semi-Arid Zone; The University of Sheffield: Sheffield, UK, 2010. 
38. Shalaby, A.; Shafey, A. Optimizing the Thermal Performance of Street Canyons in New Cairo, Egypt. Available online: https://www.researchgate.net/publication/326973081_Optimizing_the_Thermal_Performance_of_ Street_Canyons_in_New_Cairo_Egypt (accessed on 25 February 2020).

39. Fahmy, M. Climate Change Adaptation for Mid-latitude Urban Developments. In Proceedings of the PLEA2012 - 28th Conference, Lima, Perú, 7-9 November 2012.

40. Fahmy, M.; Elwy, I. Visual and Thermal Comfort Optimization for Arid Urban Spaces using Parametric Techniques on the Scale of Compactness Degree. In Proceedings of the Passive and Low Energy Architecture Conference, Los Angeles, California, USA, 11-13 July 2016.

41. NOUH. Environmental Guide for Urban; Urban Spaces; NOUH: Cairo, Egypt, 2013.

42. Hassaan, A.; Mahmoud, A. Analysis of the microclimatic and human comfort conditions in an urban park in hot and arid regions. Build. Environ. 2011, 46, 2641-2656.

43. Limona, S.; Al-hagla, K.; El-Sayed, Z. Using simulation methods to investigate the impact of urban form on human comfort. Case study: Coast of Baltim, North Coast, Egypt. Alex. Eng. J. 2019, 58, 273-282. [CrossRef]

44. Fahmy, M.; Kamel, H.; Mokhtar, H.; Elwy, I.; Gimiee, A.; Ibrahim, Y.; Abdelalim, M. On the Development and Optimization of an Urban Design Comfort Model (UDCM) on a Passive Solar Basis at Mid-Latitude Sites. Climate 2019, 7, 1. [CrossRef]

45. Fahmy, M.; Sharples, S. Urban form, thermal comfort and building CO2 emissions - a numerical analysis in Cairo. Build. Serv. Eng. Res. Technol. 2011, 32, 73-84. [CrossRef]

46. Jendritzky, G.; Nübler, W. A model analysing the urban thermal environment in physiologically significant terms. Meteorology and Atmospheric Physics 1981, 29, 313-326. [CrossRef]

47. d'Ambrosio Alfano, F.R.; Olesen, B.W.; Palella, B.I.; Pepe, D.; Riccio, G. Fifty Years of PMV Model: Reliability, Implementation and Design of Software for Its Calculation. Atmosphere 2019, 11, 49. [CrossRef]

48. Lai, A.C.K.; Mui, K.W.; Wong, L.T.; Law, L.Y. An evaluation model for indoor environmental quality (IEQ) acceptance in residential buildings. Energy Build. 2009, 41, 930-936. [CrossRef]

49. Morakinyo, T.E.; Dahanayake, K.W.D.K.C.; Ng, E.; Chow, C.L. Temperature and cooling demand reduction by green-roof types in different climates and urban densities: A co-simulation parametric study. Energy Build. 2017, 145, 226-237. [CrossRef]

50. Fahmy, M.; Sharples, S.; Trabolsi, A. Dual stage simulations to study microclimate thermal effect of trees on comfort levels in a multi family residential building. In Proceedings of the 11th International Building Performance Simulation Association Conference University of Strathclyde, Glasgow, UK, 27-30 July 2009.

51. Abdallah, A. The Influence of Urban Geometry on Thermal Comfort and Energy Consumption in Residential Building of Hot Arid Climate, Assiut, Egypt. Procedia Eng. 2015, 121, 158-166. [CrossRef]

52. Taha, H. Urban climates and heat islands: Albedo, evapotranspiration, and anthropogenic heat. Energy Build. 1997, 25, 99-103. [CrossRef]

53. McPherson, E.G.; Nowak, D.; Heisler, G.; Grimmond, S.; Souch, C.; Grant, R.; Rowntree, R. Quantifying urban forest structure, function, and value: The Chicago Urban Forest Climate Project. Urban. Ecosyst. 1997, 1, 49-61. [CrossRef]

54. Dimoudi, A.; Nikolopoulou, M. Vegetation in the Urban Environments: Microclimatic Analysis and Benefits. Energy Build. 2003, 35, 69-76. [CrossRef]

55. Avissar, R. Potential effects of vegetation on the urban thermal environment. Atmos. Environ. 1996, 30, 437-448. [CrossRef]

56. McPherson, E.G.; Simpson, J.R.; Xiao, Q.; Wu, C. Million trees Los Angeles canopy cover and benefit assessment. Landsc. Urban. Plan. 2011, 99, 40-50. [CrossRef]

57. McPherson, G.; Simpson, J.R. Shade trees as a demand-side resource. Home Energy 1995, 12, 11-17.

58. Mahmoud, A.H.A. An analysis of bioclimatic zones and implications for design of outdoor built environments in Egypt. Build. Environ. 2011, 46, 605-620. [CrossRef]

59. Fahmy, M.; Sharples, S.; Yahiya, M. LAI based trees selection for mid latitude urban developments: A microclimatic study in Cairo, Egypt. Build. Environ. 2010, 45, 345-357. [CrossRef]

60. Fahmy, M.; El-Hady, H.; Mahdy, M.; Abdelalim, M.F. On the green adaptation of urban developments in Egypt; predicting community future energy efficiency using coupled outdoor-indoor simulations. Energy Build. 2017, 153, 241-261. [CrossRef]

61. Oke, T.R. Boundary Layer Climates; Methuen: London, UK, 1987. 
62. Sailor, D.J.; Hutchinson, D.; Bokovoy, L. Thermal property measurements for ecoroof soils common in the western U.S. Energy Build. 2008, 40, 1246-1251. [CrossRef]

63. Jacobs, A.F.G.; Ronda, R.J.; Holtslag, A.A.M. Water vapour and carbon dioxide fluxes over bog vegetation. Agric. For. Meteorol. 2003, 116, 103-112. [CrossRef]

64. Kurn, M.; Bretz, S.E.; Huang, B.; Akbari, H. The Potential for Reducing Urban Air Temperatures and Energy Consumption Through Vegetative Cooling; Heat Island Project Energy \& Environment Division, Lawrence Berkeley Laboratory, University of California: Berkeley, CA, USA, 1994.

65. Streiling, S.; Matzarakis, A. Influence of single and small clusters of trees on the bio climate of a city: A case study. J. Arboric. 2003, 29, 309-315.

66. Shahidan, M.; Salleh, E.; Shariff, K. Effects of Tree Canopies on Solar Radiation Filtration In a Tropical Microclimatic Environment. In Proceedings of the 24th Conference on Passive and Low Energy Architecture, Singapore, 22-24 November 2007.

67. Lalic, B.; Mihailovic, D.T. An empirical relation describing leaf-area density inside the forest for environmental modeling. J. Appl. Meteorol. 2004, 43, 641-645. [CrossRef]

68. Bruse, M. ENVI-met V4.0, a microscale urban climate model. Available online: www.envi-met.com (accessed on 19 December 2019).

69. Fahmy, M.; El-Hady, H.; Mahdy, M. LAI and Albedo Measurements Based Methodology for Numerical Simulation of Urban Tree's Microclimate: A Case Study in Egypt. Int. J. Sci. Eng. Res. 2016, 7, 790-797.

70. LI-COR. LAI Plant Canopy Analizer. Available online: https://www.licor.com/env/products/leaf_area/LAI2200C/ (accessed on 18 September 2017).

71. KippZonen. CMP21 Pyranometer. Available online: http://www.kippzonen.com/Product/14/CMP21Pyranometer\#.WBL8a (accessed on 2 November 2019).

72. Taheri Shahraiyni, H.; Sodoudi, S.; El-Zafarany, A.; Abou El Seoud, T.; Ashraf, H.; Krone, K. A Comprehensive Statistical Study on Daytime Surface Urban Heat Island during Summer in Urban Areas, Case Study: Cairo and Its New Towns. Remote Sens. 2016, 8, 643. [CrossRef]

73. Fahmy, M.; Ibrahim, Y.; Hanafi, E.; Barakat, M. Would LEED-UHI greenery and high albedo strategies mitigate climate change at neighborhood scale in Cairo, Egypt? Build. Simul. 2018, 11, 1273-1288. [CrossRef]

74. Yasser, A. The Role of Trees in Improving Thermal Comfort and Mitigating Urban Heat Island. In Envi-Met Simulation Study of an Urban Model in Cairo City; Arabic. Cairo University: Cairo, Egypt, 2017.

75. Aboelata, A.; Sodoudi, S. Evaluating urban vegetation scenarios to mitigate urban heat island and reduce buildings' energy in dense built-up areas in Cairo. Build. Environ. 2019, 166, 106407. [CrossRef]

76. Aboelata, A.; Sodoudi, S. Evaluating the effect of trees on UHI mitigation and reduction of energy usage in different built up areas in Cairo. Build. Environ. 2020, 168, 106490. [CrossRef]

77. Duany, A. Introduction to the Special Issue: The Transect. J. Urban. Des. 2002, 7, 251-260. [CrossRef]

78. Fahmy, M.; Sharples, S. Extensive review for urban climatology: Definitions, aspects and scales. In Proceedings of the 7th International Conference on Civil and Architecture Engineering, ICCAE-7, Military Technical Collage, Cairo, Egypt, 27-29 May 2008.

79. Mahmoud, A.H.; Omar, R.H. Planting design for urban parks: Space syntax as a landscape design assessment tool. Front. Archit. Res. 2015, 4, 35-45. [CrossRef]

80. Arnold, H.F. Trees in Urban Design, 1st ed.; Van Nostrand Reinhold: New York, NY, USA, 1980.

81. Trowbridge, P.J.; Bassuk, N.L. Trees in the Urban Landscape; Site Assessment, Design and Installation; John Wiley \& Sons, Inc.: Hoboken, New Jersey, USA, 2004.

82. Lam, K.C.; Leung, S.; Hui, W.C.; Chan, P.K. Environmental Quality of Urban parks and open spaces in Hong Kong. Environ. Monit. Assess. 2005, 111, 55-73. [CrossRef]

83. Oke, T.R.; Crowther, J.M.; McNaughton, K.G.; Monteith, J.L.; Gardiner, B. The Micrometeorology of the Urban Forest and Discussion. Philos. Trans. R. Soc. Lond. Biol. Sci. 1989, 324, 335-349. [CrossRef]

84. Akbari, H. Shade trees reduce building energy use and $\mathrm{CO} 2$ emissions from power plants. Environ. Pollut. 2002, 116, S119-S126. [CrossRef]

85. Akbari, H.; Pomerantz, M.; Taha, H. Cool surfaces and Shade Trees to Reduce Energy Use and Improve Air Quality in Urban Areas. Sol. Energy 2001, 70, 295-310. [CrossRef]

86. Ayad, A.; Kamel, W.; Mohamad, F. Urban Green and Blue Infrastructure Simulation in a Changing Climate from Microclimate to Energy Consumption: A Case study in Alexandria, Egypt. In Proceedings of the Building Simulation 2019, Rome, Italy, 2-4 September 2019. 
87. Bruse, M.; Fleer, H. Simulating surface-plant-air interactions inside urban environments with a three dimensional numerical model. Environ. Model. Softw. 1998, 13, 373-384. [CrossRef]

88. Hoppe, P. The physiological equivalent temperature-A universal index for the biometeorological assessment of the thermal environment. Int. J. Biometeorol. 1999, 43, 71-75. [CrossRef] [PubMed]

89. AutoDesk. ECOTECT2010. Available online: http://www.autodesk.co.uk/adsk/servlet/mform?validate=no\& siteID=452932\&id=14205163 (accessed on 4 April 2017).

90. Chatzinikolaou, E.; Chalkias, C.; Dimopoulou, E. Urban microclimate improvement using ENVI-MET climate model. In Proceedings of the ISPRS TC IV Mid-Term Symposium on 3D Spatial Information Science-The Engine of Change, Delft, The Netherlands, 1-5 October 2018; pp. 69-76.

91. Salata, F.; Golasi, I.; de Lieto Vollaro, R.; de Lieto Vollaro, A. Urban microclimate and outdoor thermal comfort. A proper procedure to fit ENVI-met simulation outputs to experimental data. Sustain. Cities Soc. 2016, 26, 318-343. [CrossRef]

92. Crank, P.J.; Sailor, D.J.; Ban-Weiss, G.; Taleghani, M. Evaluating the ENVI-met microscale model for suitability in analysis of targeted urban heat mitigation strategies. Urban. Clim. 2018, 26, 188-197. [CrossRef]

93. Toudert, F.A. Dependence of Outdoor Thermal Comfort on Street Design in Hot and Dry Climate; Institutes der Universität Freiburg: Freiburg, Germany, 2005.

94. Onset. HOBO U30 Data Loggers. Available online: http://www.onsetcomp.com/products/data-loggers/U30data-loggers (accessed on 2 March 2018).

95. Park, S.; Tuller, S.E.; Jo, M. Application of Universal Thermal Climate Index (UTCI) for microclimatic analysis in urban thermal environments. Landsc. Urban. Plan. 2014, 125, 146-155. [CrossRef]

96. de Freitas, C.R.; Grigorieva, E.A. A comprehensive catalogue and classification of human thermal climate indices. Int. J. Biometeorol. 2015, 59, 109-120. [CrossRef]

97. d'Ambrosio Alfano, F.R.; Malchaire, J.; Palella, B.I.; Riccio, G. WBGT index revisited after 60 years of use. Ann. Occup. Hyg. 2014, 58, 955-970.

98. Cardinali, M.; Pisello, A.L.; Piselli, C.; Pigliautile, I.; Cotana, F. Microclimate mitigation for enhancing energy and environmental performance of Near Zero Energy Settlements in Italy. Sustain Cities Soc 2020, 53, 101964. [CrossRef]

99. Elwy, I.; Ibrahim, Y.; Fahmy, M.; Mahdy, M. Outdoor microclimatic validation for hybrid simulation workflow in hot arid climates against ENVI-met and field measurements. Energy Procedia 2018, 153, 29-34. [CrossRef]

100. Tedeschi, A.; Andreani, S.; Buono, A.; Degni, M.; Friesen, L.; Galli, A.; Lipari, F.; Lombardi, D.; Lonnbardi, L.; Mamou-Mani, A.; et al. AAD_Algorithms-Aided Design, Parametric Strategies using Grasshopperß; Le Penseur: Potenza, Italy, 2014.

101. McNeel, R. Rhinoceros (Version 5). Available online: https://www.rhino3d.com/features (accessed on 8 October 2017).

102. WOODBURY, R. Elements of Parametric Design; Routledge, Taylor \& Francis Group: Abingdon, Oxon, UK, 2010.

103. Olgyay, V. Design with climate; Bioclimatic Approach and Architectural Regionalism; Princeton University Press: London, UK, 1963.

104. Olgyay, V. Bioclimatic orientation method for buildings. Int. J. Biometeorol. 1967, 11, 163-174. [CrossRef]

105. Fanger, P.O. Thermal Comfort; Analysis and Applications in Environmental Engineering; McGraw-Hill: New York, NY, USA, 1970.

106. Givoni, B. Man, Climate and Architecture; Elsevier Ltd.: London, UK, 1969.

107. Givoni, B. The effect of heat capacity in direct gain buildings. Passiv. Sol. Energy 1987, 4, $25-40$.

108. DOE. EnergyPlus Energy Simulation Software. Available online: www.apps1.eere.energy.gov/buildings/ energyplus/cfm/reg_form.cfm. (accessed on 15 January 2009).

109. Fahmy, M.; Mahdy, M.; Mahmoud, S.; Abdelalim, M.; Ezzeldin, S.; Attia, S. Influence of urban canopy green coverage and future climate change scenarios on energy consumption of new sub-urban residential developments using coupled simulation techniques: A case study in Alexandria, Egypt. Energy Rep. 2020. [CrossRef]

110. CCWorldWeatherGen. Climate Change World Weather File Generator. Available online: www.serg.soton.ac. uk/ccworldweathergen/ (accessed on 20 February 2020). 
111. Ayad, A.; Fahmy, M.; Kamel, W. Urban Green and Blue Infrastructure Simulation in a Changing Climate from Microclimate to Energy Consumption: A Case study in Alexandria, Egypt. In Proceedings of the 16th IBPSA International Conference and Exhibition, Rome, Italy, 7-9 September 2019.

112. IPCC. Climate change 2014: synthesis report. Contribution of Working Groups I, II and III to the fifth assessment report of the Intergovernmental Panel on Climate Change; Intergovernmental Panel on Climate Change: Geneva, Switzerland, 2014.

113. ARUP. Weather Shift. Available online: http://www.weather-shift.com/ (accessed on 2 November 2019).

114. Mahmoud, S.; Fahmy, M.; Mahdy, M.; Elwy, I.; Abdelalim, M. Comparative energy performance simulation for passive and conventional design: A case study in Cairo, Egypt. Energy Rep. 2020. [CrossRef]

115. IPCC. Climate Change 2014: Synthesis Report; IPCC: Geneva, Switzerland, 2014; p. 151.

116. EPA. Reducing Urban Heat Islands: Compendium of Strategies; Cool Pavements. Available online: http: //www.epa.gov/heatisland/resources/compendium.htm. (accessed on 14 September 2009).

117. EPA. Reducing Urban Heat Islands: Compendium of Strategies; Cool Roofs. Available online: http://www.epa.gov/ heatisland/resources/compendium.htm. (accessed on 14 September 2009).

118. Santamouris, M. Cooling the cities-a review of reflective and green roof mitigation technologies to fight heat island and improve comfort in urban environments. Sol. Energy 2014, 103, 682-703. [CrossRef]

119. Al-Hafith, O.; BK, S.; Bradbury, S.; de Wilde, P. The Impact of Courtyard parameters on its shading level An experimental study in Baghdad, Iraq. Energy Procedia 2017, 134, 99-109. [CrossRef]

120. Al-Hafith, O.; Satish, B.K.; Bradbury, S.; de Wilde, P. The impact of courtyard compact urban fabric on its shading: Case study of Mosul city, Iraq. Energy Procedia 2017, 122, 889-894. [CrossRef]

121. Al-Hafith, O.; Satish, B.K.; Bradbury, S.; Wilde, P.D. Simulation of courtyard spaces in a desert climate. Energy Procedia 2017, 142, 1997-2002. [CrossRef]

122. Li, H.; Zhou, Y.; Wang, X.; Zhou, X.; Zhang, H.; Sodoudi, S. Quantifying urban heat island intensity and its physical mechanism using WRF/UCM. Sci. Total Environ. 2019, 650, 3110-3119. [CrossRef]

123. Li, H.; Wolter, M.; Wang, X.; Sodoudi, S. Impact of land cover data on the simulation of urban heat island for Berlin using WRF coupled with bulk approach of Noah-LSM. Theor. Appl. Climatol. 2018, 134, 67-81. [CrossRef]

124. LadybugTools. Dragonfly. Available online: https://www.ladybug.tools/dragonfly.html (accessed on 20 December 2019).

125. Roudsari, M.S. What is Ladybug Tools? Available online: http://www.ladybug.tools/ (accessed on 18 November 2017).

126. Mackey, C.; Galanos, T.; Norford, L.; Roudsari, M.S. Wind, Sun, Surface Temperature, and Heat Island: Critical Variables for High-Resolution Outdoor Thermal Comfort. In Proceedings of the 15th IBPSA Conference, San Francisco, CA, USA, 7-9 August 2017.

127. Bueno, B.; Nakano, A.; Norford, L.; Reinhart, C. Urban Weather Generator-A Novel Workflow for Integrating Urban Heat Island Effect within Urban Design Process. Available online: http://www.ibpsa.org/proceedings/ BS2015/p2909.pdf (accessed on 25 February 2020).

128. Naboni, E.; Natanian, J.; Brizzi, G.; Florio, P.; Chokhachian, A.; Galanos, T.; Rastogi, P. A digital workflow to quantify regenerative urban design in the context of a changing climate. Renew. Sustain. Energy Rev. 2019, 113, 109255. [CrossRef]

129. METEONORM. Irradiation Data for Every Place on Earth. Available online: www.meteonorm.com (accessed on 25 January 2018).

130. Nielsen, C.K. Hygrotermic Control of the Microclimate Around Buildings. Technical University of Denmark: Copenhagen, Denmark, 2018.

131. Manickathan, L.; Defraeye, T.; Allegrini, J.; Derome, D.; Carmelieta, J. Parametric study of the influence of environmental factors and tree properties on the transpirative cooling effect of trees. Agric. For. Meteorol. 2017, 248, 259-274. [CrossRef]

132. OpenFOAM. OpenFOAM. Available online: https://openfoam.org/ (accessed on 20 December 2019).

133. Kottek, M.; Grieser, J.; Beck, C.; Rudolf, B.; Rubel, F. World Map of the Köppen-Geiger climate classification updated. Meteorol. Zeitschrif 2006, 15, 259-263. [CrossRef]

134. Rheologic. Rheologic. Available online: https://rheologic.net/en (accessed on 20 December 2019). 
135. Horvath, A.; Nagy, J. uhiSolver-Developing an effective transient Multi-Physics Solver for prediction and mitigation of Urban Heat Island dynamics. In Proceedings of the 6th ESI OpenFOAM User Conference, Hamburg, Germany, 23-25 October 2018.

136. Li, H.; Zhou, Y.; Li, X.; Meng, L.; Wang, X.; Wu, S.; Sodoudi, S. A new method to quantify surface urban heat island intensity. Sci. Total Environ. 2018, 624, 262-272. [CrossRef] [PubMed]

137. HBRC. Egyptian Code for Reducing Energy Consumption in Residentail Buildings; Egyptian Ministry of Housing, Utilities and Urban Communities; Housing and Building Research Centre: Cairo, Egypt, 2008.

138. EGBC. Green Pyramid Rating System, 1st ed.; The Housing and Building National Research Center (HBRC), The Egyptian Green Building Council (EGBC): Cairo, Egypt, 2011.

139. Nikolopoulou, M.; Steemers, K. Thermal comfort and psychological adaptation as a guide for designing urban spaces. Energy and Buildings 2003, 35, 95-101. [CrossRef]

140. Hegazy, I.R.; Moustafa, W.S. Toward revitalization of new towns in Egypt case study: Sixth of October. Int. J. Sustain. Built Env. 2013, 2, 10-18. [CrossRef]

141. Peng, C.; Huang, Y.; Wu, Z. Building-integrated photovoltaics (BIPV) in architectural design in China. Energy Build. 2011, 43, 3592-3598. [CrossRef]

142. Hulme, M. $1.5^{\circ} \mathrm{C}$ and climate research after the Paris Agreement. Nat. Clim. Chang. 2016, 6, $222-224$. [CrossRef]

143. Brunnée, J.; Streck, C. The UNFCCC as a negotiation forum: Towards common but more differentiated responsibilities. Clim. Policy 2013, 13, 589-607. [CrossRef]

144. Disch, R. The energy plus buildings in the solar settlement of Freiburg, Germany. Available online: http://www.rolfdisch.de/en/architects-office/ (accessed on 7 February 2020).

145. EU. EU Research and Innovation Magazine. Available online: https://horizon-magazine.eu/article/recordbreaking-solar-cells-get-ready-mass-production.html (accessed on 7 February 2020).

146. NUCA. Social Housing. Available online: http://www.newcities.gov.eg/about/Projects/Housing_projects/ SocialHousing/default.aspx (accessed on 14 February 2020).

(C) 2020 by the authors. Licensee MDPI, Basel, Switzerland. This article is an open access article distributed under the terms and conditions of the Creative Commons Attribution (CC BY) license (http://creativecommons.org/licenses/by/4.0/). 